\title{
Portfolio Optimization
}

\author{
Anna Nagurney \\ John F. Smith Memorial Professor \\ Department of Finance and Operations Management \\ Isenberg School of Management \\ University of Massachusetts \\ Amherst, Massachusetts 01003
}

Advanced Management Development Program in Real Estate Harvard University Graduate School of Design

July 24, 2009 


\section{We are in a New Era of Decision-Making Characterized by:}

- complex decision-making among decision-makers in organizations;

- alternative and at times conflicting criteria used in decision-making;

- constraints on resources: natural, human, financial, time, etc.;

- high impact of many decisions;

- increasing risk and uncertainty, and

- the importance of dynamics and realizing a fast and sound response to evolving events. 


\section{Portfolio Optimization Models, Tools, and Techniques can greatly assist in Complex Decision-Making Today!}

Also, portfolio optimization models and tools serve as the building blocks for a spectrum of system-wide models. 


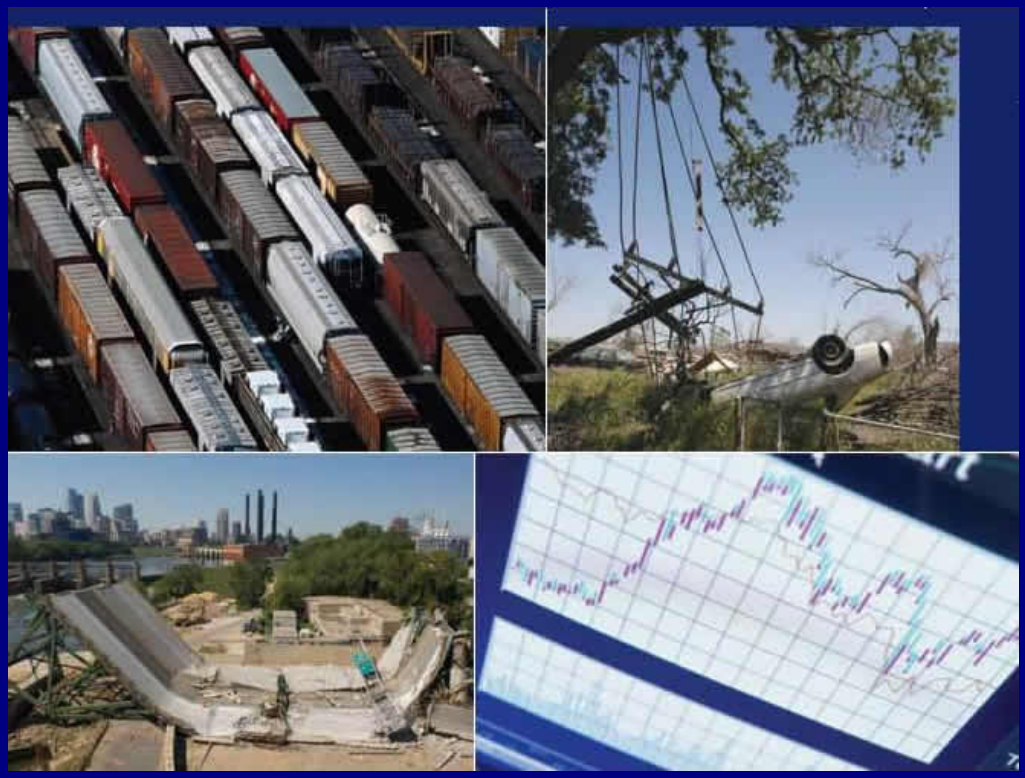

Source - Fragile Networks: Identifying Vulnerabilities and Synergies in an Uncertain World (Nagurney and Qiang (2009)). 
- In this lecture, we present some principles from both economics and finance that form the foundations of modern portfolio

optimization. Rather than presenting a superficial coverage of a wide range of topics, the discussion is concentrated on issues that are fundamental.

- We first provide a brief historical overview, describing the evolution of financial economics during the past several decades so that the reader can understand better its current state and its progression through time.

- We then present some basic fundamentals of utility theory and risk, followed by a detailed look at the behavior of markets, and, more precisely, at the process by which asset allocation and prices are determined, discussing concepts such as market efficiency and equilibrium. 
- We then focus in this lecture on issues related to international economics and finance, where emphasis is given on elements that rarely, if ever, are encountered by single economy applications (e.g., multiple currencies, different tax systems, etc.).

We also interweave some new and novel approaches that can enhance financial decision-making. 


\section{Foundations of Financial Economics}

Financial economic theory was founded on several major theoretical breakthroughs in economic theory and has evolved into the tool that governs every financial market worldwide today.

Moreover, it provides a solid framework for the study and the development of financial markets and its products. 
The theory of financial economics, whose development has been very rapid, is a mixture of many different theories among which the theories of finance and economics, optimization, and utility theory are credited with the biggest contributions.

In particular, economic and financial theories offer the theoretical background needed for the accurate representation of problems, whereas optimization is the tool that materializes and solves what the two previous theories suggest.

Lastly, utility theory provides the background needed for handling risk and uncertainty. Obviously, any advance in any of these areas has an immediate effect on financial economics. 


\section{Historic Overview}

The current state of modern financial economic theory is based upon the innovative work of brilliant economists in the decade of the 1950s.

\section{Many of those whose work we will be mentioning in this lecture:} Arrow, Debreu, Samuelson, Markowitz, Miller, Sharpe, Modigliani, Merton, Scholes, and Tobin have been awarded the Nobel Prize in

\section{Economic Sciences.}

The first major breakthrough was by Arrow and Debreu, who, in a series of extraordinary publications (Arrow (1951), Debreu (1951), Arrow (1953), Arrow and Debreu (1954), Debreu (1959)), introduced a simple, but significant, extension to the existing economic theory. Their contributions brought competitive equilibrium theory to a new level and provided the appropriate environment for the birth of modern economic and finance theory. 
In particular, Arrow and Debreu, through the use of the techniques of convexity and fixed point theory, showed that the viability and the efficiency of the existing market system were open to analysis, with a model that followed the neoclassical economic foundations of: market clearing, uncertainty, and individual rationality.

Subsequently, they derived new fundamental economic properties from these models (e.g., Arrow (1969), Debreu (1970)) and provided significant economic interpretations to the results. 


\section{chosen price system must always exist.}

These conditions realistically defined the way that an economy should behave, in terms of the commodities, the firms, and the consumers and their preferences, in order to have the supply and the demand equally and simultaneously determine a price in equilibrium. It was the first time that precise, detailed assumptions were used to show that the model was consistent. 
With the definition of the Arrow-Debreu type economy, standard theorems on the existence, uniqueness, and Pareto optimality (the allocation of goods in a way that no displacement can benefit one consumer unless it harms another (cf. Pareto (1909)) could be reinterpreted. Moreover, for the first time, an efficient allocation of resources became possible under uncertainty.

The connection between competitive equilibrium and Pareto optimality was redefined in a more solid way, without the need of strong assumptions. The equivalence between an Arrow-Debreu equilibrium and a Pareto optimum was demonstrated with the first and second theorems of welfare economics that Arrow and Debreu simultaneously published in 1951 . 
Even though some of the ideas that were introduced through their work were perceived much earlier (e.g., the connection between Pareto optimality and competitive equilibrium), most of the ideas were in either a stage of confusion, or not interconnected with each other in a single framework, and, consequently, issues such as the existence and the uniqueness of equilibrium under uncertainty could not be adequately addressed. 
Almost simultaneous to the innovative work of Arrow and Debreu, two other major theoretical developments were taking place. The first one was by Modigliani and Miller (1958), who, in a challenging and controversial paper, established that the capital structure of a firm, that is, the financial framework of the firm, usually measured by the debt to equity ratio, does not affect the value of a firm.

As a result, there is no optimal mix of securities that a firm can issue to finance its assets; simply stated, there is no optimal debt to equity ratio to characterize the financial structure of a firm.

their work, for the first time, the idea of financial arbitrage was

used by stating that any investor can use riskless arbitrage in order

to avoid the financial structure of a firm. Their model and

approach served as the base for most of the research on capital structure and are considered to be the birth of modern capital structuring. 


\section{Historical Data - Some Exchange Traded Fund Data}

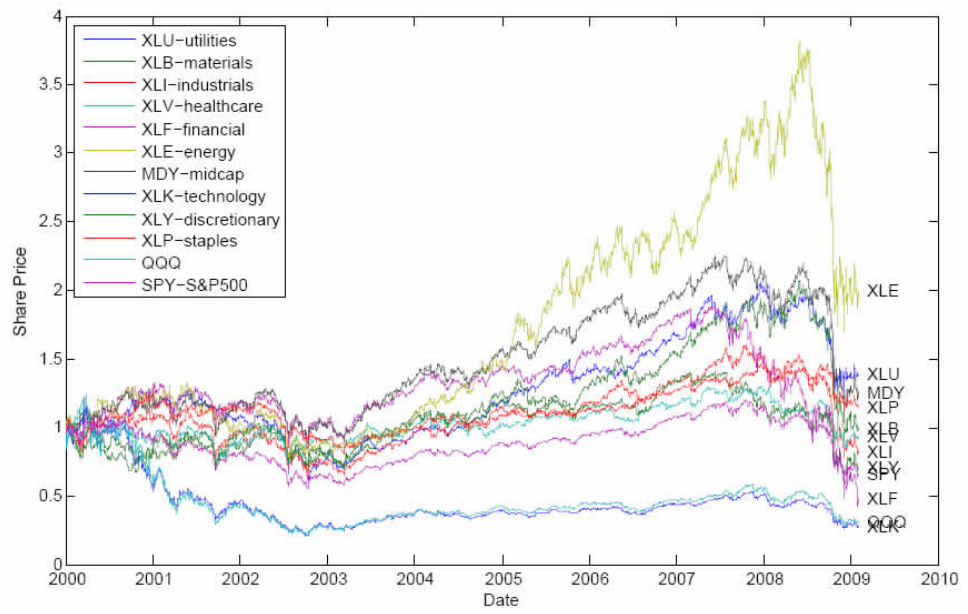

$S_{j}(t)=$ share price for investment $j$ at time $t$. 
Return Data: $R_{j}(t)=\frac{S_{j}(t)}{S_{j}(t-1)}$

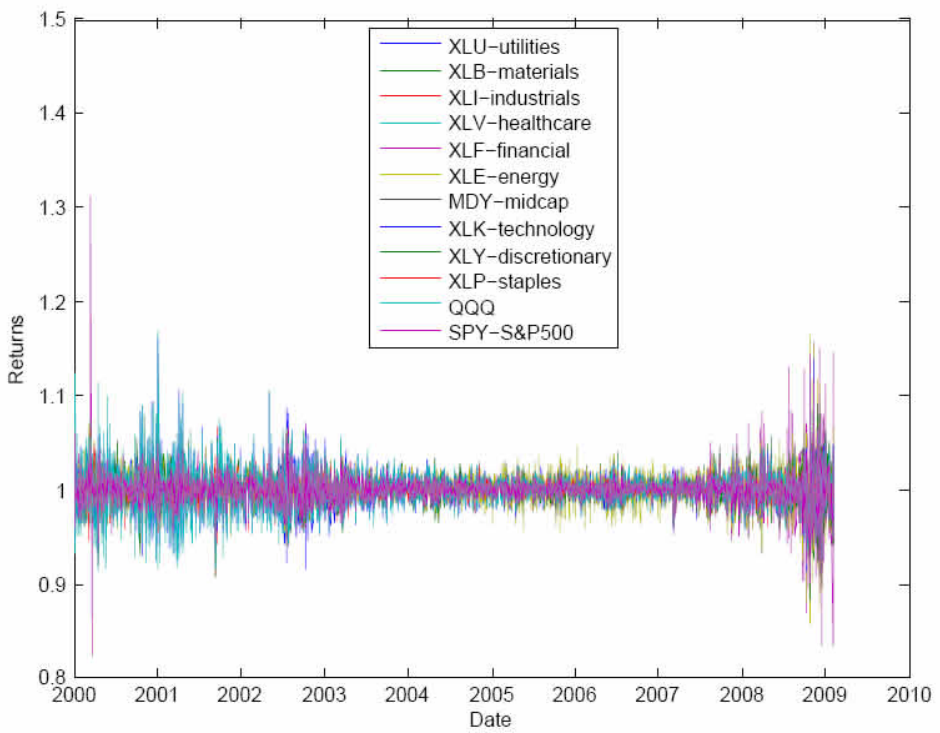

Volatility is easy to see but mean return is not. 


\section{The Markowitz Model}

The other theoretical breakthrough was by Markowitz in 1952, who is credited with the birth of modern portfolio theory. Markowitz determined that one of the principal objectives of investors, besides the maximization of the returns of their portfolios, is to diversify away as much risk as possible.

He claimed that investors select assets in such a way that the risk of their portfolio matches their risk preferences. In other words, he suggested that individuals who cannot bear risk will invest in assets with low risk, whereas people more comfortable with risk will accept investments of higher risk.

His work also suggested that the tradeoff between risk and return is different for each investor, but the preferences of all people lie upon a fictitious curve (cf. Figure) which is usually called the "frontier of efficient portfolios." 


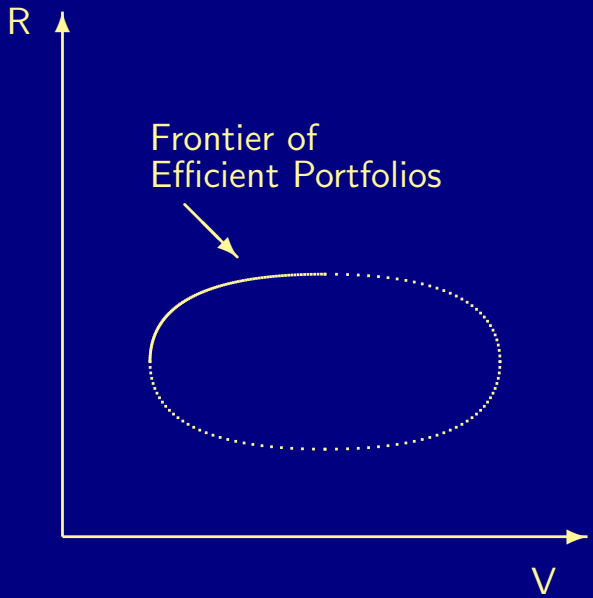

Figure: The Efficient Frontier 
Along this curve lie all the diversified portfolios that have the highest return for a given risk, or the lowest risk for a given return. Markowitz's model was based on mean-variance portfolio selection, where the average and the variability of portfolio returns were determined in terms of the mean and covariance of the corresponding investments. 


\section{Risk}

Table: Which of these two yearly returns would you prefer?

\begin{tabular}{|c|c|c|}
\hline Year & Portfolio \#1 & Portfolio \#2 \\
\hline 1 & 100. & 100. \\
\hline 2 & 100. & 200. \\
\hline 3 & 100. & 0. \\
\hline 4 & 100. & 10. \\
\hline 5 & 100. & 200. \\
\hline Ave. & 100. & 102. \\
\hline
\end{tabular}

Let us measure the deviation from the average:

Portfolio \#1: 0

Portfolio \#2:

$\left((102-100)^{2}+(102-200)^{2}+(102-0)^{2}+(102-10)^{2}+(102-200)^{2}\right.$

Variance is like the average deviation from the average and helps to quantify risk. 
More analytically, let $n$ be the total number of securities available in the economy, and let $X_{i}$ represent the relative amount of capital invested in security $i$. Let random variable $r_{i}$ denote the rate of return of security $i$. Then the rate of return for a portfolio, denoted by $r_{p}$, composed of all these securities is given by:

$$
r_{p}=r_{1} X_{1}+r_{2} X_{2} \ldots+r_{n} X_{n} .
$$


According to probability theory, the mean of a weighted sum (as in $(1))$ is the weighted sum of the expected values, and, as a result, the expected rate of return of the portfolio, $R=E\left(r_{p}\right)$, is given by:

$$
R=E\left(r_{p}\right)=\sum_{i=1}^{n} E\left(r_{i}\right) X_{i},
$$

where $E\left(r_{i}\right)$ denotes the expected value of the return on security $i$. If we now let $\mu_{i}$ denote the expected value of the return on security $i$, then equation (2) can be simplified to:

$$
R=\sum_{i=1}^{n} \mu_{i} X_{i} .
$$


Unfortunately, the variance of a weighted sum is not as simple to derive as is the mean. Again, turning to probability theory, the variance of a weighted sum, and, consequently, the variance on the return of the portfolio, $V$, is given by:

$$
V=\sum_{i=1}^{n} X_{i}^{2} \operatorname{Var}\left(r_{i}\right)+2 \sum_{i=1}^{n} \sum_{\substack{j=1 \\ j \neq i}}^{n} X_{i} X_{j} \sigma_{i j},
$$

where $\operatorname{Var}\left(r_{i}\right)$ is the variance of return on security $i$ defined as:

$$
\operatorname{Var}\left(r_{i}\right)=E\left[\left(r_{i}-\mu_{i}\right)^{2}\right],
$$

and $\sigma_{i j}$ denotes the covariance between securities $i$ and $j$, where

$$
\sigma_{i j}=E\left[\left(r_{i}-\mu_{i}\right)\left(r_{j}-\mu_{j}\right)\right] .
$$


Obviously, $\operatorname{Var}\left(r_{i}\right)=\sigma_{i i}$, and, hence, equation (4) can be written as:

$$
V=\sum_{i=1}^{n} \sum_{j=1}^{n} X_{i} X_{j} \sigma_{i j}
$$

Equivalently, $V=X^{T} Q X$, where $Q$ is called the variance-covariance matrix.

Markowitz suggested that, for a fixed set of expected values $\mu_{i}$ and covariances $\sigma_{i j}$ of the returns of all assets $i$ and $j$, every investor can find an $(R, V)$ combination that better fits his taste, solely limited by the constraints of the specific problem. 
In other words, if we assume that the enclosed area in the Figure is the set of all possible $(R, V)$ combinations, then the investor must choose a combination that provides the highest return for a given risk, or the lowest risk for a given return. The set of these best combinations, which forms the frontier of efficient portfolios, is depicted. 
The paper by Markowitz (1952), however, did not provide any specific techniques for determining this set of efficient portfolios although it contained a small illustration of how this set can be determined geometrically. In the original model by Markowitz short sales were excluded, and, thus,

$$
X_{i} \geq 0, \quad i=1, \ldots, n,
$$

and the amount of capital available was limited up to a budget.

Hence, the summation over all relative amounts invested in all securities had to be equal to one, that is,

$$
\sum_{i=1}^{n} X_{i}=1
$$


According to the original work of Markowitz (1952), the efficient frontier had to be identified and then every investor had to select a portfolio through a mean-variance analysis that fitted his preferences. This notion was then extended and presented as a mathematical optimization model by Markowitz (1959), where every investor had to determine his optimal portfolio holdings through the solution of a quadratic programming model similar to:

$$
\text { Maximize } \quad \alpha R-(1-\alpha) V
$$

subject to:

$$
\begin{gathered}
\sum_{i=1}^{n} X_{i}=1 \\
X_{i} \geq 0, \quad i=1, \ldots, n,
\end{gathered}
$$

where $\alpha$ denotes an indicator of how risk-averse a specific investor is. 


\section{An Example}

Suppose that an investor wishes to construct a portfolio, drawing from a set of 3 independent candidate stocks. The rates of return of these investments are given in the table below along with the associated probabilities. We will demonstrate how the Markowitz model can determine the best combination of stocks in order to maximize the expected rate of return and to minimize the risk adjusted by the investor' $\mathrm{s}$ attitude towards the risk, given $\alpha=1$, $\alpha=0.5$ and $\alpha=0$.

Table: Possible Outcomes of Candidate Stocks

\begin{tabular}{|c|c|c|c|}
\hline & Rate of Return 1 & Rate of Return 2 & Rate of Return 3 \\
\hline Stock 1 & $5 \%$ & $10 \%$ & $15 \%$ \\
\hline Stock 2 & $2 \%$ & $20 \%$ & $22 \%$ \\
\hline Stock 3 & $0 \%$ & $20 \%$ & $30 \%$ \\
\hline Probability & 0.3 & 0.6 & 0.1 \\
\hline
\end{tabular}




\section{Solution:}

Calculate the expected rates of returns, the variances and the covariances of these stocks, using the formulas introduced above.

Expected Returns:

$$
\begin{aligned}
& \mu_{1}=E\left(r_{1}\right)=0.3 \times 5 \%+0.6 \times 10 \%+0.1 \times 15 \%=9.0 \% \\
& \mu_{2}=E\left(r_{2}\right)=0.3 \times 2 \%+0.6 \times 20 \%+0.1 \times 22 \%=14.8 \% \\
& \mu_{3}=E\left(r_{3}\right)=0.3 \times 0 \%+0.6 \times 20 \%+0.1 \times 30 \%=15.0 \%
\end{aligned}
$$

\section{Variances:}

$$
\begin{aligned}
& V\left(r_{1}\right)=0.3 \times(5 \%-9 \%)^{2}+0.6 \times(10 \%-9 \%)^{2}+0.1 \times(15 \%-9 \%)^{2} \\
& =0.0009 \\
& \begin{aligned}
V\left(r_{2}\right)=0.3 \times(2 \%-14.8 \%)^{2}+ & 0.6 \times(20 \%-14.8 \%)^{2}+0.1 \times(22 \%-14.8 \%)^{2} \\
= & 0.007056 \\
V\left(r_{3}\right)=0.3 \times(0 \%-15 \%)^{2}+ & 0.6 \times(20 \%-15 \%)^{2}+0.1 \times(30 \%-15 \%)^{2} \\
= & 0.0105
\end{aligned}
\end{aligned}
$$


Since these three stocks are assumed to be independent of one other, the covariances are equal to zero.

Putting these results into tables, we obtain:

Table: Expected Rates of Returns

\begin{tabular}{|c|c|c|c|}
\hline & Stock 1 & Stock 2 & Stock 3 \\
\hline Expected Rates & $9 \%$ & $14.8 \%$ & $15 \%$ \\
\hline
\end{tabular}

Table: Variance/Covariance Matrix

\begin{tabular}{|l|c|c|c|}
\hline & Stock 1 & Stock 2 & Stock 3 \\
\hline Stock 1 & 0.0009 & 0 & 0 \\
\hline Stock 2 & 0 & 0.007056 & 0 \\
\hline Stock 3 & 0 & 0 & 0.0105 \\
\hline
\end{tabular}




\section{The Model Formulation:}

Let $X_{i}$ represent the relative amount of capital invested in Stock $i$; $i=1,2,3$.

Maximize $\alpha\left(.09 X_{1}+.148 X_{2}+.15 X_{3}\right)-(1-\alpha)\left(0.0009 X_{1}^{2}+0.007056 X_{2}^{2}\right.$ $\left.+0.0105 X_{3}^{2}\right)$

subject to:

$$
\begin{gathered}
X_{1}+X_{2}+X_{3}=1 \\
X_{i} \geq 0, \quad i=1,2,3 .
\end{gathered}
$$

Solving the models with $\alpha=1,0.5,0$, using a software code:

Table: The Optimal Solutions of the Mean-Variance Models

\begin{tabular}{|c|c|c|c|c|}
\hline & Stock 1 & Stock 2 & Stock 3 & Optimal Value \\
\hline$\alpha=1$ & 0 & 0 & 1 & 0.15 \\
\hline$\alpha=0.5$ & 0 & 0.5411 & 0.4589 & 0.0723 \\
\hline$\alpha=0$ & 0.8242 & 0.1051 & 0.0706 & -0.0007 \\
\hline
\end{tabular}




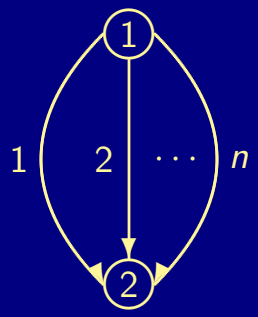

Figure: Network Structure of the Classical Markowitz Model 


\section{Useful Formulae Associated with Risk}

Variance $(X)=E\left[(X-E(X))^{2}\right]=E\left(X^{2}\right)-(E(X))^{2}$

Covariance $(X, Y)=E[(X-E(X))(Y-E(Y))]$.

Recall that $E$ denotes the expected value. 


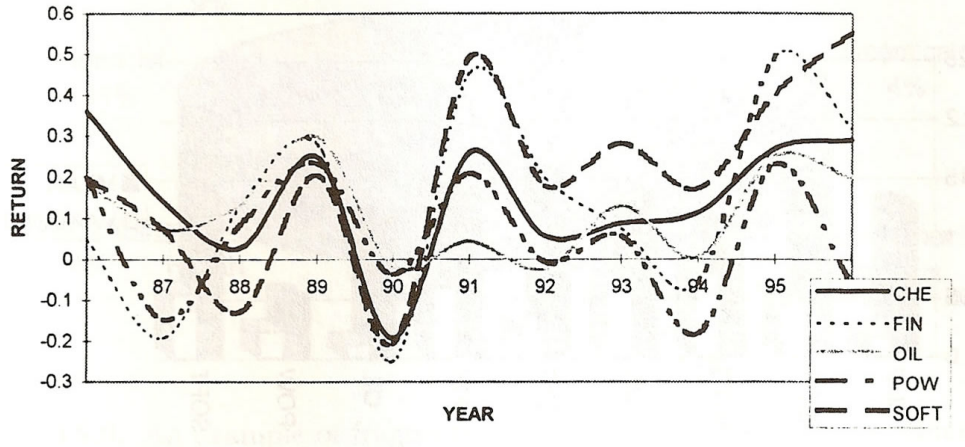

Returns of Some Stock Groups in the S\&P 500 (1986-1996) 


\section{RETURN}

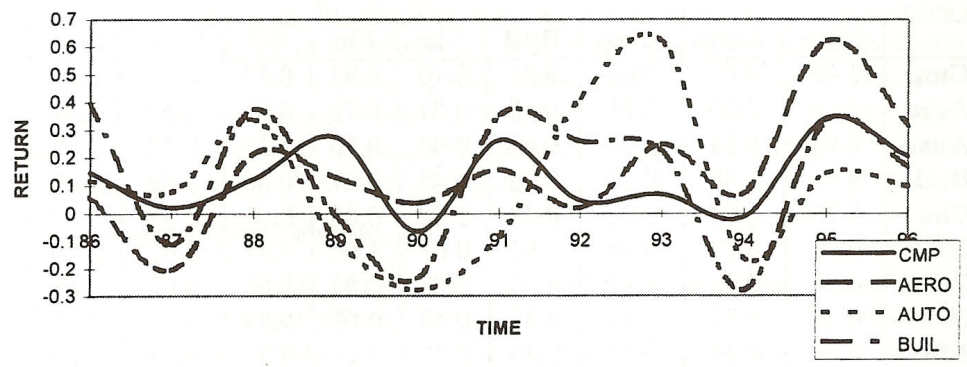

Returns of Some Additional Stock Groups in the S\&P 500 (1986-1996) 


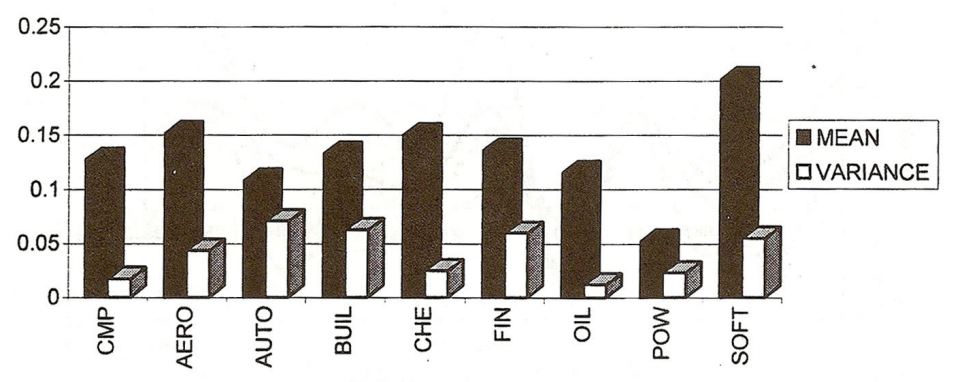

STOCK TYPES

Mean and Variance on the Returns of Some Stock Groups in the S\&P 500 (1986-1996) 
Table: Correlation Matrix on Returns of Some Stock Groups in the S\&P 500 (1986-1996)

\begin{tabular}{|l|c|c|c|c|c|c|c|c|c|}
\hline & Cmp & Aero & Auto & Buil & Che & Fin & Oil & Pow & Soft \\
\hline Cmp & 1.00 & 0.68 & 0.03 & 0.61 & 0.75 & 0.91 & 0.77 & 0.79 & 0.67 \\
Aero & 0.68 & 1.00 & 0.21 & 0.48 & 0.31 & 0.72 & 0.56 & 0.51 & 0.49 \\
Auto & 0.03 & 0.21 & 1.00 & 0.60 & 0.05 & 0.18 & 0.11 & 0.10 & 0.12 \\
Buil & 0.61 & 0.48 & 0.60 & 1.00 & 0.48 & 0.67 & 0.36 & 0.68 & 0.40 \\
Che & 0.75 & 0.31 & 0.05 & 0.48 & 1.00 & 0.63 & 0.65 & 0.47 & 0.77 \\
Fin & 0.91 & 0.72 & 0.18 & 0.67 & 0.63 & 1.00 & 0.51 & 0.67 & 0.76 \\
Oil & 0.77 & 0.56 & 0.11 & 0.36 & 0.65 & 0.51 & 1.00 & 0.62 & 0.38 \\
Pow & 0.79 & 0.51 & 0.10 & 0.68 & 0.47 & 0.67 & 0.62 & 1.00 & 0.29 \\
Soft & 0.67 & 0.49 & 0.12 & 0.40 & 0.77 & 0.76 & 0.38 & 0.29 & 1.00 \\
\hline
\end{tabular}


Many versions and extensions of Markowitz's model have appeared in the literature, a collection of which can be found in Francis and Archer (1979), with $\alpha=1 / 2$ being a frequently accepted value.

In the subsequent decade, for the first time, Grubel (1968) documented the gains from internationally diversified portfolios, starting a new era in international macroeconomics which witnessed significant progress in the years that followed.

Furthermore, most of the economic and finance literature focused on the extension of the Arrow-Debreu model to financial markets (cf. Hirshleifer (1965)), and on the improvement of the full-covariance model by Markowitz, which required massive calculations in order to determine the efficient frontier and to perform a portfolio analysis. 


\section{The Sharpe Model}

\section{The first important simplification of Markowitz's model was}

suggested by Sharpe (1963), through a model known as the diagonal model, where "the individual covariances between all securities are assumed to be zero."

According to Sharpe's model, the variance-covariance matrix has zeros in all positions other than the diagonal, and, therefore, the variance on the return of a portfolio is given by:

$$
V=\left(\begin{array}{c}
X_{1} \\
X_{2} \\
\vdots \\
X_{n}
\end{array}\right)^{T}\left(\begin{array}{ccccc}
\sigma_{11}^{2} & 0 & 0 & \ldots & 0 \\
0 & \sigma_{22}^{2} & 0 & \ldots & 0 \\
\vdots & \ddots & \ddots & \ddots & \vdots \\
0 & 0 & 0 & \ldots & \sigma_{n n}^{2}
\end{array}\right)\left(\begin{array}{c}
X_{1} \\
X_{2} \\
\vdots \\
X_{n}
\end{array}\right)
$$


In the Sharpe model the number of covariances required for portfolio analysis was smaller, and, consequently, the solution process was simplified, requiring less data and less computation time. 


\section{Financial Network Models with Multiple Sectors}

The need to expand upon the Markowitz and Sharpe frameworks in order to capture interactions among investors / sectors / decision-makers let to financial system network models. Such models began with the work of Nagurney and Hughes (1992) in the estimation of financial flow of funds accounts.

The book by Nagurney and Siokos (1997) documents the evolution of financial networks models to that date. 


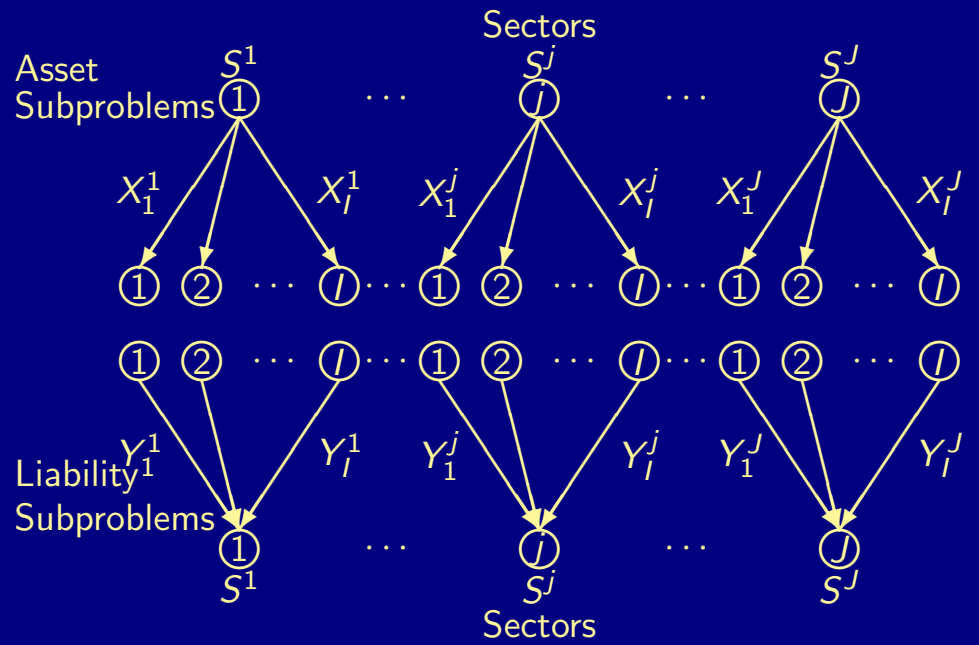

Figure: Network Structure of Multiple Financial Sectors' Portfolio Optimization Problems 


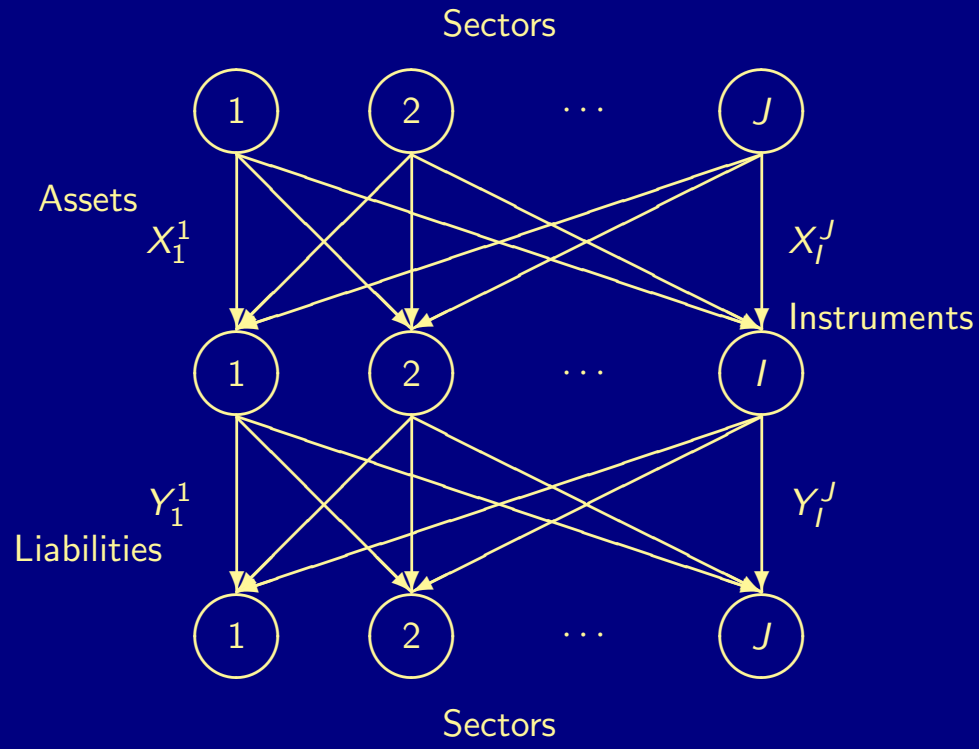

Figure: The Network Structure at Equilibrium 


\section{A Numerical Example (from Nagurney and Siokos (1997))}

Assume that there are two sectors in the economy and three financial instruments. Assume that the "size" of each sector in terms of its financial holdings is given by $S^{1}=1$ and $S^{2}=2$. The variance-covariance matrices of the two sectors are:

$$
Q^{1}=\left(\begin{array}{cccccc}
1 & .25 & .3 & 0 & 0 & 0 \\
.25 & 1 & .1 & 0 & 0 & 0 \\
.3 & 1 & 1 & 0 & 0 & 0 \\
0 & 0 & 0 & 1 & .2 & .3 \\
0 & 0 & 0 & .2 & 1 & .5 \\
0 & 0 & 0 & .3 & .5 & 1
\end{array}\right)
$$

and

$$
Q^{2}=\left(\begin{array}{cccccc}
1 & 0 & .3 & 0 & 0 & 0 \\
0 & 1 & .2 & 0 & 0 & 0 \\
.3 & .2 & 1 & 0 & 0 & 0 \\
0 & 0 & 0 & 1 & .5 & 0 \\
0 & 0 & 0 & .5 & 1 & .2 \\
0 & 0 & 0 & 0 & .2 & 1
\end{array}\right)
$$


The equilibrium pattern:

Equilibrium Prices:

$$
r_{1}^{*}=.34039, \quad r_{2}^{*}=.23805, \quad r_{3}^{*}=.42156,
$$

\section{Equilibrium Asset Holdings:}

$$
\begin{aligned}
& X_{1}^{1^{*}}=.27899, \quad X_{2}^{1^{*}}=.31803, \quad X_{3}^{1^{*}}=.40298, \\
& X_{1}^{2^{*}}=.79662, \quad X_{2}^{2^{*}}=.60904, \quad X_{3}^{2^{*}}=.59434,
\end{aligned}
$$

Equilibrium Liability Holdings:

$$
\begin{aligned}
& Y_{1}^{1^{*}}=.37081, \quad Y_{2}^{1 *}=.43993, \quad Y_{3}^{1 *}=.18927, \\
& Y_{1}^{2^{*}}=.70579, \quad Y_{2}^{2 *}=.48693, \quad Y_{3}^{2 *}=.80729 .
\end{aligned}
$$




\section{Financial Networks with Intermediation}

The conceptualization of financial systems as networks dates to (Quesnay (1758)) who depicted the circular flow of funds in an economy as a network. His basic idea was subsequently applied to the construction of flow of funds accounts, which are a statistical description of the flows of money and credit in an economy (Nagurney and Hughes (1992)).

There are now general financial network models that capture the complexity of financial interactions on a macro level (see Nagurney and Siokos (1997), Nagurney (2003), and Nagurney (2008)). 


\section{Sources of Funds}

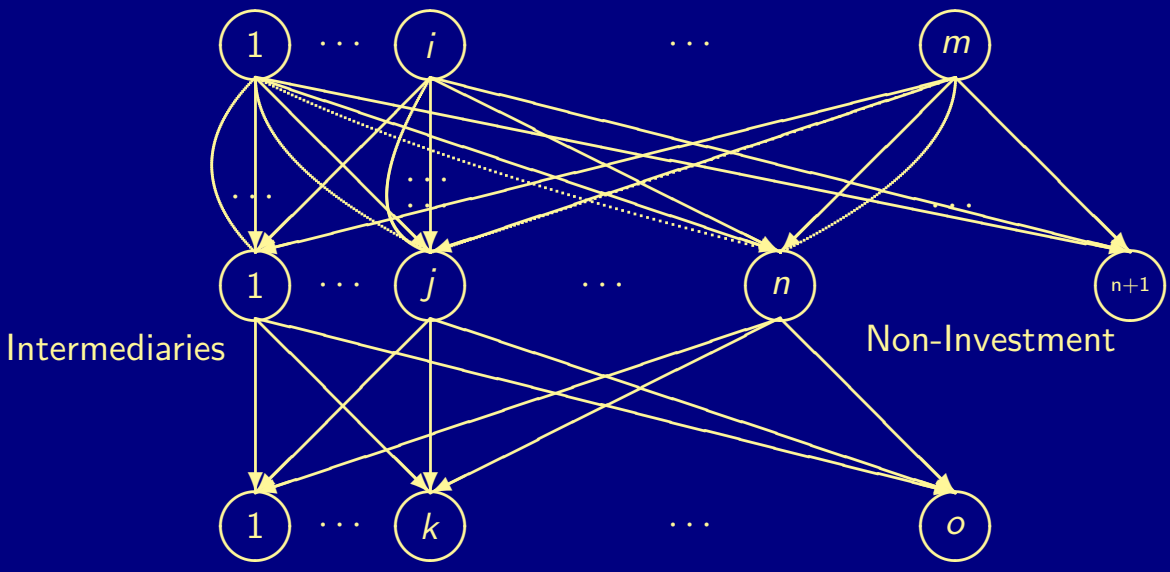

Demand Markets - Uses of Funds

Figure: The Network Structure of the Financial Economy with Intermediation and with Non-Investment Allowed 


\section{The Capital Asset Pricing Model}

One of the most significant extension of the models by Markowitz (1952) and Sharpe (1963), was the Capital Asset Pricing Model (CAPM), which was based on the work of Sharpe (1964), Lintner (1965), and Mossin (1966).

In this model the concept of a risk-free asset and market portfolio were introduced. A risk-free asset is an asset with a positive expected rate of return and a zero standard deviation, with the US Treasury bill being a good example. 
A market portfolio, on the other hand, is a portfolio on the efficient frontier of the Markowitz model which is considered to be desirable by all investors.

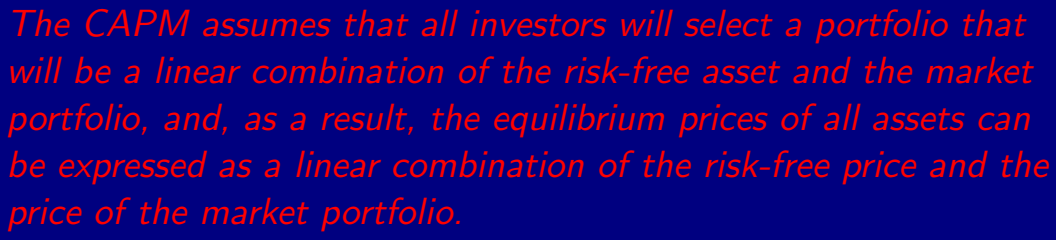


More precisely, the CAPM suggested, for the first time, a simple but, yet, important relationship between the risk and the return of an asset, given by:

$$
E\left(r_{j}\right)=r_{f}+(1-\alpha) \operatorname{cov}\left(r_{j}, \pi\right)+\alpha \operatorname{cov}\left(r_{j}, r_{m}\right),
$$

where $E\left(r_{j}\right)$ denotes the expected nominal rate of return of asset $j$, $r_{f}$ is the rate of return of the risk-free asset, $r_{m}$ denotes the nominal rate of return of the market portfolio, $\pi$ is the rate of inflation, and $\alpha$ is the market average degree of aversion. It must be pointed out that in equation (10) the sum of the coefficient of the covariance with inflation and the coefficient of the covariance with market portfolio is equal to one. Consequently, in the case that investors are risk neutral, that is, when $\alpha=0$, then all the existing risk is due to inflation. 


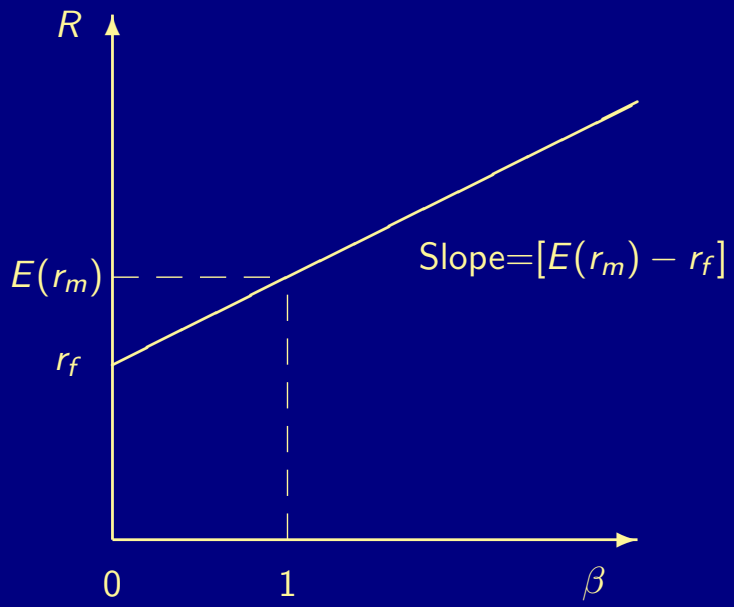

Figure: Illustration of risk factor $\beta$ 
Another version of the CAPM, which is more commonly used in corporate finance, and which gives the expected rate of return of asset $j$ in a more compact and simple format, without having to deal directly with risk aversion and inflation, is given by:

$$
E\left(r_{j}\right)=r_{f}+\beta_{j}\left[E\left(r_{m}\right)-r_{f}\right]
$$

where $E\left(r_{m}\right)$ denotes the expected rate of return of the market portfolio. $\beta_{j}$ represents the correlation of asset $j$ with the overall market and is defined as:

$$
\beta_{j}=\operatorname{Cov}\left(r_{m}, r_{j}\right) / \operatorname{Var}\left(r_{m}\right),
$$

where $\operatorname{Cov}\left(r_{m}, r_{j}\right)$ denotes the covariance between the rate of return of asset $j$ and the rate of return of the market portfolio, and $\operatorname{Var}\left(r_{m}\right)$ represents the variance of the rate of return of the market portfolio. The factor, $\beta_{j}$, denotes how risky an asset $j$ is as compared to the overall market. 
As is illustrated in the Figure, if beta $(\beta)$ is equal to one, then the corresponding asset behaves, on the average, like the entire market, whereas a beta equal to zero represents a risk-free asset.

The assumptions of the CAPM concern the investors, the firms, and the structure of the existing capital market. Investors are assumed to be risk-averse, trying to maximize utility functions that can be expressed in terms of the mean and the variance of the returns. Moreover, returns are assumed to be normally distributed, and investors to be price takers with homogeneous expectations and without any tax obligations. 
All the firms are assumed to be equity financed and the market is assumed to be perfect, which means that there are no transaction costs and that the investors cannot influence the price of any product in the economy.

Obviously, some of the assumptions governing the CAPM were not realistic and, as a result, the model was extended and improved several times in the years that followed. Everyone, however, is in agreement in that it was one of the major breakthroughs in modern economic and finance theory and forms the basis for most of the financial models that exist in our day. 
Most of the major extensions of the CAPM occurred in the decade of the seventies, where a series of papers either relaxed some of its assumptions, or derived empirical results by applying it to a series of problems.

Among the most significant contributions of that time were: the extension to a multiperiod economy by Merton (1973), the consumption CAPM by Breeden (1978) (which, however, failed empirically due to the difficulty in observing and computing consumption), and, finally, the inclusion of transaction costs by Milne and Smith (1980).

The empirical tests of the CAPM were controversial for quite some time. The first publications documented a reasonable fit between the data and the model's outcome, and, as a result, more practitioners began to favor it. Scientists, in turn, were thoroughly investigating new aspects of testing its validity, and some criticism arose (e.g., Roll (1969), Blume and Friend (1973), Roll (1977)) as to the methodologies that were used for the empirical tests in the preceding years. 


\section{Arbitrage Pricing Theory}

The dissatisfaction with the empirical tests of the CAPM led to more advanced models, such as the Arbitrage Pricing Theory (APT) by Ross (1976), which then became the subject of important research.

\section{APT's biggest contribution was the inclusion of multiple risk factors and the generalization of the CAPM, which was considered to be a special case of APT with only a single risk factor.}


According to APT, there is a linear relation among the expected returns of all assets in the economy. In particular, Ross assumed that the rate of return of every security can be expressed as a linear combination of some "basic" risk factors. If we let $N$ denote the total number of such factors, then a security's rate of return satisfies a factor structure given by:

$$
r_{j}=E\left(r_{j}\right)+\sum_{k=1}^{N} f_{k} \beta_{j k}+e_{j},
$$

where the $f_{k}$ 's are common random factors, the $\beta_{j k}$ 's are coefficients, and the $e_{j}$ 's are the security specific residuals with $E(f)=0, E\left(e_{j}\right)=0$, and $E\left(f e_{j}\right)=0$, where $f$ is the vector with components: $\left\{f_{1}, \ldots, f_{N}\right\}$. 
The factors used in APT are "nondiversifiable" and not preidentified by the model, and, as a result, empirical results were not easily obtainable. Finally, in his paper, Ross showed that, in order to obstruct arbitrage, the expected rates of return of every security must be given by:

$$
E\left(r_{j}\right)=r_{f}+\sum_{k=1}^{N} \beta_{j k}\left[E\left(f_{k}\right)-r_{f}\right],
$$

where $r_{f}$ is the risk-free rate of return. 


\section{Black and Scholes Model}

Another major development was the derivation of an accurate option pricing model by Black and Scholes (1973), which revolutionized the pricing of financial instruments and the entire financial industry. We recall that an option is, in general, the right to trade an asset for a preagreed amount of capital. If the right is not exercised after a predetermined period of time, the option expires and the holder loses the money paid for holding that right.

As is to be expected, a large part of the subsequent literature focused on different approaches to, simplifications of, and variations of the Black and Scholes Model (BSM). A significant simplification of the BSM was done by Cox, Ross, and Rubinstein (1979), and an important application was demonstrated by Merton (1974) as to the pricing of corporate debt. The Black and Scholes (1973) model managed to offer a simple but reliable tool for option pricing, where the number of variables that determine an option price is small and the derivation of their value is simple. 
At the same time, a series of new models and studies (e.g., Lessard (1973), Solnik (1974)) suggested that international portfolios outperform domestically diversified portfolios.

\section{Furthermore, the mean-variance portfolio analysis that was}

introduced and mathematically formulated by Markowitz (1952,

1959), and later simplified by the diagonal model of Sharpe (1963),

was further extended by Pogue (1970) and Francis (1978), with the introduction of variance-covariance matrices for both assets and liabilities, applied to the asset-liability management of banks.

Moreover, dynamical programming was used to formulate and solve equilibrium models with asset prices and capital accumulation processes. One of the classic financial models of this ilk is the asset pricing model of Lucas (1978), where special restrictions give the (Arrow-Debreu type) economy a recursive structure. 
During the decade of the eighties, most of the aforementioned models and theories were extended and improved. The Arbitrage Pricing Theory of Ross was refined by Chamberlain (1983) and Connor (1984), and the model of Black and Scholes was further explored and significantly generalized (see, e.g., Duffie and Huang (1985), Cox, Ingersoll, and Ross (1985), Duffie (1986)). The type of economy defined by Arrow and Debreu was established as the common ground for both financial modeling and macroeconomics, verifying their parallel evolution. 
The theoretical advances of the preceding years, along with the increased volatility of interest and currency exchange rates, led to the increase in the number and the type of financial products.

An entirely new financial industry with ever larger sized problems and higher computational demands evolved, and, consequently, there was a need for new advances in economic and finance theory. Among the biggest challenges was the introduction of mathematical tools and frameworks that could capture the complexities of such large-scale problems. 
Many techniques, from the entire spectrum of mathematical programming (linear, nonlinear, stochastic, and network optimization) were utilized in order to solve a large variety of financial economics problems. In particular, because of the interest that practitioners and monetary authorities demonstrated for the modeling and the computation of solutions to financial applications, a significant part of the literature focused on these topics. 


\section{Utility Theory and Risk Aversion}

A large portion of economic and finance theory is based on the assumption that a decision-maker, given a choice of several alternatives, can, and, will be able to, select one of them, depending on his preferences.

\section{We now outline some basic concepts of utility theory which form the framework for the preference relationships among different alternatives. We limit our discussion to fundamental issues.}


The concepts of utility and risk can stand alone as the main subject of a book, and, therefore, an exhaustive presentation would not be possible here. The goal of this section is to present, in very general terms, some basics of utility theory in order to familiarize the reader with some important ideas.

Beginning in the nineteenth century, a series of economists, including Jevons (1871) and Walras (1874), were considering utility to be measurable by each consumer. According to them, every consumer had a cardinal measure of utility, and, hence, every commodity had a specific number representing the degree of utility that was associated with it. This number was something like a price for each commodity and could be added or compared. For example, commodity $X$ could be "liked" ten times more than commodity $Y$, and, therefore, commodity $X$ was ten times more preferable to commodity $Y$. 
This early interpretation of utility was based on a series of strong assumptions and theorems. Its flexibility and usefulness, hence, became limited, mostly due to the fact that each commodity had a different number assigned by each consumer and, consequently, the study of a large number of commodities and consumers was prohibitive.

Therefore, a new approach to modeling utility was synthesized (cf. Samuelson (1947), Edwards (1992), and Keeney and Raiffa (1993)). According to it, consumers would rank their preferences instead of assigning specific numbers to them. 
In order to understand this approach to utility theory, let $\mathcal{K}$ be the set of all alternatives that a consumer has, and assume that there are $n$ different alternatives, which are denoted as: $\left(x_{1}, x_{2}, \ldots, x_{n}\right)$. A decision-maker is assumed to be able to rank all the alternatives according to his preferences and we assume that labeling is such that $x_{1}$ is less preferred than $x_{2}$ and so on. The symbolic representation is then:

$$
x_{1} \prec x_{2} \prec \ldots \prec x_{n} .
$$

The real-valued function $u(x)$ that represents the preference relation " $\prec$ " is a utility function, provided that:

$$
x_{i} \prec x_{j} \Longrightarrow u\left(x_{i}\right) \prec u\left(x_{j}\right) .
$$




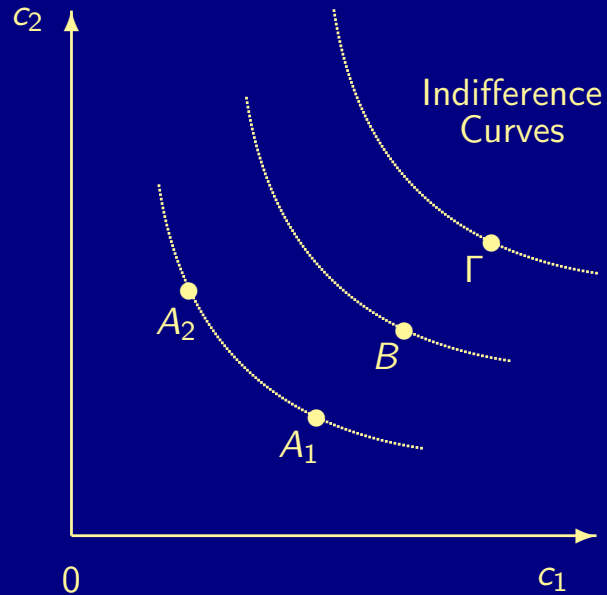

Figure: An Indifference Map 
Each alternative decision corresponds to a specific combination of commodities, and, consequently, a utility function can also be stated in terms of the quantities that the decision-maker (investor) consumes (invests) from each commodity (asset).

Let $c_{i}$ represent the quantity that the decision-maker consumes of commodity $i$, and assume, for simplicity, that the consumer has a choice only between two commodities. Hence, the utility function can be represented as:

$$
u=f\left(c_{1}, c_{2}\right)
$$

A decision-maker can derive a particular level of satisfaction from a variety of different $\left(c_{1}, c_{2}\right)$ combinations. The set of all these combinations is called an indifference curve and the collection of many indifference curves of different levels of satisfaction is called an indifference map. 
An example of an indifference map is shown in the Figure, where the quantities of $c_{1}$ and $c_{2}$ are measured along the axes. Points $A_{1}$ and $A_{2}$ refer to $\left(c_{1}, c_{2}\right)$ combinations that offer the same level of satisfaction.

According to the definition, indifference curves never intersect and they correspond to higher levels of satisfaction as one moves further up and to the right as in the Figure. 
In other words, point $\Gamma$ is more preferable than point $B$ and points $A_{1}$ and $A_{2}$ are less preferable than points $B$ and $\Gamma$.

In financial economics, satisfaction is measured in terms of wealth and the utility function is assumed to be characterized by several properties (cf. Samuelson (1947), Levy and Sarnat (1977), Henderson and Quandt (1980), Stapleton and Subrahmanyam (1980), Huang and Litzenberger (1988)). The first property is that of positive marginal utility of wealth, which states that more wealth is preferred to less wealth.

Hence, an investor will always select the portfolio that will increase his wealth, and his preferences will not have any social or emotional input. 
More wealth in a well functioning economy means that more capital will be spent, so that personal needs and desires can be fulfilled.

The second property is that of the diminishing marginal utility of wealth, which states that the more a product is consumed, the less satisfaction it brings to the decision-maker.

For example, most people who do not have a car will enjoy purchasing one because a car will significantly improve their every day life. For some individuals a second car may even be important and useful for a variety of reasons. An individual may purchase a van, a general utility vehicle, or a sports car because it is needed or simply because one enjoys driving it. A third car becomes less desirable by most individuals, and a fourth is out of the question for almost everyone, and so on. 


\section{But why do decision-makers behave in this manner?}

The answer is simple and comes directly out of the diminishing marginal utility of wealth property. At one point, the cost of getting another car exceeds the pleasure that a person receives out of owning it, and, therefore, an individual will not consider purchasing another one. 
Now we will introduce and discuss some qualitative properties of utility functions. Each of these properties reflects a specific attitude of the corresponding investor.

The qualitative properties of a utility function form the basis upon which computational procedures for the solution of problems in financial economics have been developed. Provided that the utility function corresponds to a specific attitude by the investor, then the utility function is limited up to a degree and, hence, it is much easier to analyze and study.

Without loss of generality, we will assume that utility functions are continuous, monotonically increasing, and twice continuously differentiable. 
It must be pointed out that in many models in the existing literature, additional assumptions such as separability, additivity, and homogeneity of the utility functions are required to hold. For reasons of completeness, we now define these properties for utility functions, and, for simplicity, we follow the same notation as in (17).

A utility function is said to be strongly separable in all of its arguments if it can be written as

$$
u=F\left[\sum_{i=1}^{m} f_{i}\left(c_{i}\right)\right],
$$

where $F$ and $f_{i}$ are increasing functions and $m$ is the number of commodities. Similarly, a utility function is said to be strongly additive in all of its arguments if it can be written as

$$
u=\sum_{i=1}^{m} f_{i}\left(c_{i}\right),
$$

where, again, the $f_{i}$ are increasing functions for all $i$. 
Finally, a utility function defined on a feasible set $\mathcal{K}$ is said to be homogeneous of degree $\phi$, if, for a constant $\phi$ and any positive number $q$ such that $\left(q c_{1}, q c_{2}, \ldots, q c_{m}\right) \in \mathcal{K}$, the following holds:

$$
f\left(q c_{1}, q c_{2}, \ldots, q c_{m}\right)=q^{\phi} f\left(c_{1}, c_{2}, \ldots, c_{m}\right) .
$$


One of the primary functions of financial markets is to transfer risk among different participants of the economy.

\section{Every decision in financial economics includes a degree of risk, and, as a consequence, the entire financial industry has been built upon the effort of reducing and controlling risk.}

This attempt at diminishing risk comes out of the fact that most of the participants in the economy are, in general, risk-averse, or, in other words, conservative towards risk. 
Obviously, noone is risk-averse always and in all situations. Most individuals are risk-averse when it comes to money, but they may still pay for a lottery where their chances to win are only one in a million.

In practice, however, and in the corresponding literature, decision-makers are considered to be risk-averse. As a result, a clear mathematical description must be given in order to incorporate risk aversion in models of financial economics. 
Consider a decision-maker who is facing a lottery with two possible outcomes. Let $w_{1}$ be the desired outcome, and let $w_{2}$ be the less favorable outcome. Clearly, the expected outcome of the lottery $\bar{w}$ is equal to $\left(w_{1}+w_{2}\right) / 2$.

Assume now that the decision-maker has a choice between getting $\bar{W}$ and playing the lottery. If he decides to stay out of the lottery and get $\bar{w}$, then we say that he is risk-averse. The decision-maker believes that the satisfaction that he will get out of the certainty is higher than the one that he will get out of the lottery.

In other words, for a risk-averse decision-maker, the utility of the expected value of the result of an uncertain situation exceeds the expected utility of that result, which can be expressed mathematically as:

$$
u[E(\bar{w})]>E[u(\bar{w})] .
$$


Since the notion of risk aversion should be clear, we will now present the way that risk aversion can be estimated, and we will study the relationship between risk aversion and the utility function of a given investor. According to classic utility theory (cf. Von Winterfeldt and Edwards (1986), Keeney and Raiffa (1993)), an investor is risk-averse (prone), if and only if, his utility function is concave (convex).

For example, consider the lottery that we presented above and assume that the probability of event $w_{1}$ is $p_{1}$ and the probability of event $w_{2}$ is $p_{2}$, so that $p_{1}+p_{2}=1$, with $p_{1}, p_{2} \in[0,1]$. Then the expected outcome of the lottery $\bar{w}$ is:

$$
\bar{w}=p_{1} w_{1}+p_{2} w_{2} .
$$

If we now combine (21) and (22), we obtain:

$$
u\left[p_{1} w_{1}+p_{2} w_{2}\right]>p_{1} u\left(w_{1}\right)+p_{2} u\left(w_{2}\right),
$$

which satisfies the definition of a concave function. 
On the other hand, if we consider the same lottery as before, and also assume that the utility function of the decision-maker is concave, then:

$$
u\left[\sum_{i=1}^{2} p_{i} w_{i}\right]>\sum_{i=1}^{2} p_{i} u\left(w_{i}\right),
$$

which is equivalent to (21), and, hence, the decision-maker is risk-averse. 
Now that a connection between risk and utility functions has been established, we will define two indicators of risk aversion, suggested by Pratt (1964), which can be computed through the utility function of every decision-maker. The first indicator measures absolute risk aversion, and in the case that $u$ is monotonically increasing, and has only the single argument of "wealth," is defined as:

$$
\alpha(w)=-\frac{\frac{\partial^{2} u(w)}{\partial w^{2}}}{\frac{\partial u(w)}{\partial w}}=-\frac{\partial}{\partial w}\left[\log \frac{\partial u(w)}{\partial w}\right] .
$$

Similarly, the second indicator measures relative risk aversion, and is defined as:

$$
r(w)=-\frac{\frac{\partial^{2} u(w)}{\partial w^{2}} w}{\frac{\partial u(w)}{\partial w}} .
$$


If wealth $w$ is assumed to be positive, the two indicators are always of the same sign. It has been proved (see Keeney and Raiffa (1993)) that, if either $\alpha(w)$ or $r(w)$ is positive (negative) for all $w$, then $u$ is concave (convex), and the decision-maker is risk-averse (prone). In particular, if $u$ is increasing, $\frac{\partial u(w)}{\partial w}$ is positive. If now $\alpha(w)$ or $r(w)$ is also positive, then $\frac{\partial^{2} u(w)}{\partial w^{2}}$ must be negative and, consequently, $u$ is concave. With a similar approach one can verify the convex case. 
For completeness, we illustrate the derivation of the degree of risk aversion for the case of two commonly used utility functions, through the following simple examples.

\section{Example}

Consider the quadratic utility function:

$$
u(w)=\eta+\delta w+\gamma w^{2}
$$

where $\delta>0, \gamma>0$. Then the absolute risk aversion indicator is equal to:

$$
\alpha(w)=\frac{2 \gamma}{\delta+2 \gamma w}>0,
$$

and the relative risk aversion indicator is given by:

$$
r(w)=\frac{2 w \gamma}{\delta+2 \gamma w}>0,
$$

and, therefore, the decision-maker with utility function $u$ given by (27) is risk-averse. 


\section{Example}

Consider the logarithmic utility function:

$$
u(w)=\ln (w) .
$$

Then the absolute risk aversion indicator is given by:

$$
\alpha(w)=-\frac{-1 / w^{2}}{1 / w}=\frac{1}{w}>0,
$$

and the relative risk aversion indicator is equal to:

$$
r(w)=-\frac{-\left(1 / w^{2}\right) w}{1 / w}=1>0,
$$

and, therefore, the decision-maker with the utility function $u$ given by $(30)$ is also risk-averse. Notice that for the logarithmic utility function the degree of relative risk aversion does not depend on wealth and is equal to one. This feature of a logarithmic utility function makes it a useful tool in some international macroeconomic models. 
As it has been already pointed out, one of the main characteristics of financial economics is uncertainty. Consequently, the ability to derive the utility function for an investor under uncertainty is crucial. The work of Von Neumann and Morgenstern (1947), Savage (1954), Luce and Raiffa (1957), and Fishburn (1970) made such a task possible by defining the sets of axioms that a utility function must satisfy in order to be derived. These axioms are usually very general, but sufficient enough to imply the existence of the corresponding utility functions. 


\section{Market Equilibrium}

Most of the literature in financial economics has been based on the assumption that investors cannot affect the prices at which they buy or sell. Each investor is considered to be an isolated case, who tries to maximize his utility function, subject to the prices that the market provides him. All the participants in the economy, be they buyers or sellers, have as a goal the maximization of their profits and the minimization of their losses. The prices are derived through the market where investors constantly buy and sell commodities. 
The analysis of market equilibrium tries to determine the prices at which different products will be bought and sold, and also the amount of each product that each participant in the economy will hold in an equilibrium state.

Market equilibrium analysis has its roots in the last half of the nineteenth century. The work of Gossen (1854), Jevons (1871), and Walras (1874) initiated the analysis of equilibrium theory.

Subsequently, in the 1930s the study of market equilibrium became more formal and solid. The work of Wald $(1935,1936)$ and Hicks (1939) provided, for the first time, proofs of different qualitative properties of the equilibrium, along with a detailed study of the conditions under which an equilibrium could be modeled and derived. Furthermore, the innovative work of Arrow (1951) and Debreu (1951) started a new era in equilibrium analysis by bringing uncertainty into equilibrium theory, which led to the current status of market equilibrium theory. 
Subsequently, a series of models that combined classical economic theory and equilibrium analysis under uncertainty were developed. A characteristic example of that evolution of equilibrium theory was the innovative work of Tobin $(1963,1969,1971)$, who developed a partial equilibrium model under uncertainty for the financial sector of the economy, based on the classical Walrasian (1874) theory. The Tobin-Walras approach is on two levels, with one incorporating the utility functions of the participants, and the other the supply and demand functions of the financial instruments, where econometric techniques can then be applied for their estimation. 
The basic assumption that governs most of the existing models that address the theory of market equilibrium is that of perfect competition. Perfect competition prohibits any participant in the economy (buyer or seller) from having control over the prices of different products or over the actions of other participants.

The price of a product is considered to be a variable, the value of which is determined by the combined actions of all the buyers and sellers. Buyers are, hence, "price takers," in that they modify their holdings of a product according to the price, ignoring the effects that their behavior may have on that price. 
Perfect competition assumes that all participants in the economy have perfect information about the products available, the current price, and the bids of a specific product. Moreover, the number of the participants in the economy is assumed to be large enough so that the market activity regarding a specific product will be small compared to the transactions in the overall market.

Furthermore, all buyers are identical from the sellers' points of view and all sellers are identical from the buyers' points of view. In other words, sellers (buyers) do not prefer a specific buyer (seller) for any other reason except for the fact that he gives them a better deal. It is also assumed that all participants in the economy have access to all the different transactions that may occur. Since both buyers and sellers are informed about the price of a product, noone can either charge more or pay less than the price that exists in the market. 
The mechanism that derives the prices of specific products and the amount that will be bought or sold by a particular investor is governed by the aggregated supply and demand functions of every instrument. Assume that there are $n$ instruments with a typical instrument denoted by $i$, and $m$ investors with a typical investor denoted by $j$. The aggregated demand $D_{i}=D_{i}\left(p_{i}\right)$ of an instrument $i$ at a given price $p_{i}$ is the summation of the total demands for that instrument by all investors. The total demand for instrument $i$ is, hence, given by:

$$
D_{i}\left(p_{i}\right)=\sum_{j=1}^{m} d_{i}^{j}\left(p_{i}\right),
$$

where $d_{i}^{j}\left(p_{i}\right)$ denotes the demand for instrument $i$ by investor $j$ at price $p_{i}$. Similarly, one can define the total supply $S_{i}=S_{i}\left(p_{i}\right)$ of instrument $i$, as:

$$
S_{i}\left(p_{i}\right)=\sum_{j=1}^{m} s_{i}^{j}\left(p_{i}\right),
$$

with $s_{i}^{j}\left(p_{i}\right)$ being the supply of instrument $i$ by investor $j$ at $p_{i}$. 


\section{Equilibrium occurs when the total supply and the total demand are}

equal (assuming a positive price) for each instrument in the

\section{economy.}

The price at which this equilibrium takes place for each instrument is called the "equilibrium price" of the instrument. As it is, typically, assumed in the literature and, as is shown in the Figure, we will implicitly consider the demand function $D_{i}$ for every instrument $i$ to be of negative slope, and the supply function $S_{i}$ to be of positive slope.

Geometrically, one can say that the point at which the curves of demand and supply intersect is an equilibrium. Market equilibrium theory (under appropriate assumptions) guarantees that the market will force the price to go to its equilibrium state. 


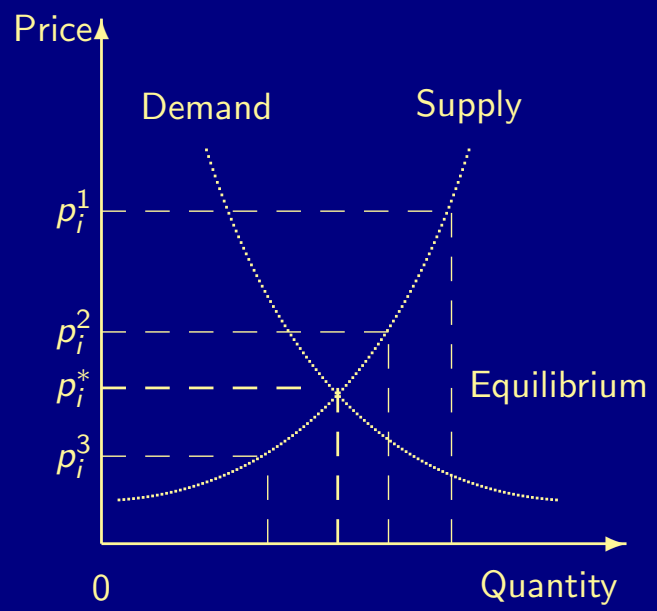

Figure: Market Equilibrium 
For example, let us assume that, initially, the market price for instrument $i$ is $p_{i}^{1}$, and that this price is higher than the equilibrium price $p_{i}^{*}$. Because of this situation, at one point investors will decide that it is not worth paying this price for the corresponding instrument $i$ and, as a result, they will stop demanding it. Therefore, the sellers of the instrument will see the buyers' reaction and they will reduce the price to a lower level.

If this level is still higher than the equilibrium price, say, at $p_{i}^{2}$, then, even though some people will be willing to buy it, eventually the demand for it will fall again and, consequently, the price will have to be reduced even further. 
If, on the other hand, the price falls below the equilibrium price, say, to $p_{i}^{3}$, then many buyers will be willing to purchase the product because they will consider the price to be favorable. Some of the buyers, however, will not get as much of the instrument as they would like to, and, in order to make the sellers prefer them, rather than the other consumers, will make a higher bid.

Obviously, the sellers will agree with the investors that offer the higher offer and the price will increase. This process will continue until the equilibrium state of instrument $i$, where $D_{i}\left(p_{i}^{*}\right)=S_{i}\left(p_{i}^{*}\right)$, is reached, at which the desires of all the participants are satisfied and instrument $i$ will have its equilibrium price $p_{i}^{*}$. 


\section{benefit from buying or selling that instrument.}

Under the assumption of perfect competition and of nonnegative instrument prices, a significant part of the literature suggests the following economic equilibrium conditions: For each instrument $i$; $i=1, \ldots, n$ :

$$
S_{i}\left(p_{i}^{*}\right)-D_{i}\left(p_{i}^{*}\right) \begin{cases}=0, & \text { if } p_{i}^{*}>0 \\ \geq 0, & \text { if } p_{i}^{*}=0 .\end{cases}
$$

Specifically, the system of equalities and inequalities (35) states that if the price of a financial instrument is positive in equilibrium, then the market must clear for that instrument and if the price is zero, then either there is an excess supply of that instrument in the economy or the market clears. 
Of course, certain changes in the market will affect the equilibrium state and, hence, the equilibrium conditions governing the instruments will change.

For example, the incorporation of taxes or transaction costs would shift the supply curve, and, as a result, the point of intersection of the demand and the supply curves will be different.

If, for example, we assume that the price of an instrument is limited (due to price policy interventions by monetary authorities) and let $p_{i}^{F}\left(p_{i}^{C}\right)$ denote the minimum (maximum) (also known as the floor (ceiling)) price of the instrument, then the economic equilibrium conditions (2.35) are then modified thus: For each instrument $i ; i=1, \ldots, n$ :

$$
S_{i}\left(p_{i}^{*}\right)-D_{i}\left(p_{i}^{*}\right) \begin{cases}\leq 0, & \text { if } p_{i}^{*}=p_{i}^{C} \\ =0, & \text { if } p_{i}^{F} \leq p_{i}^{*} \leq p_{i}^{C} \\ \geq 0, & \text { if } p_{i}^{*}=p_{i}^{F} .\end{cases}
$$


Moreover, other issues such as the existence, the uniqueness, and the stability of the equilibrium need to be addressed for each specific problem.

Market equilibrium theory is divided into two major categories, that of general and that of partial equilibrium. Partial equilibrium considers only a specific part of the economy, while the influences from the rest of the world are considered to be fixed and held constant.

On the contrary, in general equilibrium the whole economy is analyzed. Furthermore, partial equilibrium considers only groups of individuals (or sectors) and products from a specific industry (e.g., financial), ignoring the status of other parts of the economy. 
Financial equilibrium modeling and analysis provide a useful tool for financial analysts and practitioners since the role of financial equilibrium is of increasing importance in many applications in the real world.

Also, system-wide risk can then be appropriately assessed, which is
critical in today's networked and highly interconnected economies. 


\section{In 2008 and 2009, the world reeled from the effects of the financial}

\section{credit crisis; leading financial services and banks closed (including}

\section{the investment bank Lehman Brothers), others merged, and the}

\section{financial landscape was changed for forever.}

The domino effect of the U.S. economic troubles rippled through overseas markets and pushed countries such as Iceland to the verge of bankruptcy. The root of the financial problems was considered to have stemmed from the U.S. housing market and the huge number of bad loans that could not be repaid.

Ultimately, businesses could not obtain financial resources because so many banks and financial institutions were failing, which caused millions of people lost their homes. The Figure shows the increasing number of home foreclosures over the years. 


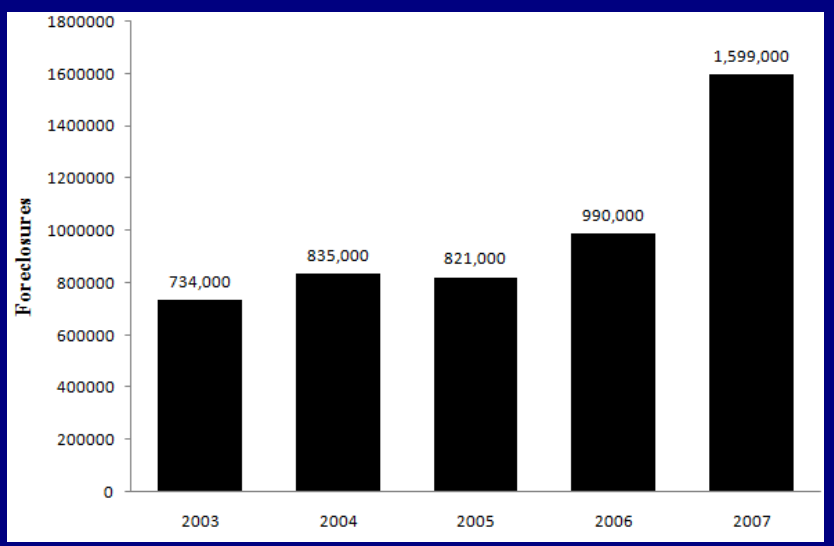

Figure: Number of Homes Entering Foreclosure (Source: Office of the Speaker of the U.S. House of Representatives (2008)) 


\section{Sources of Financial Funds}

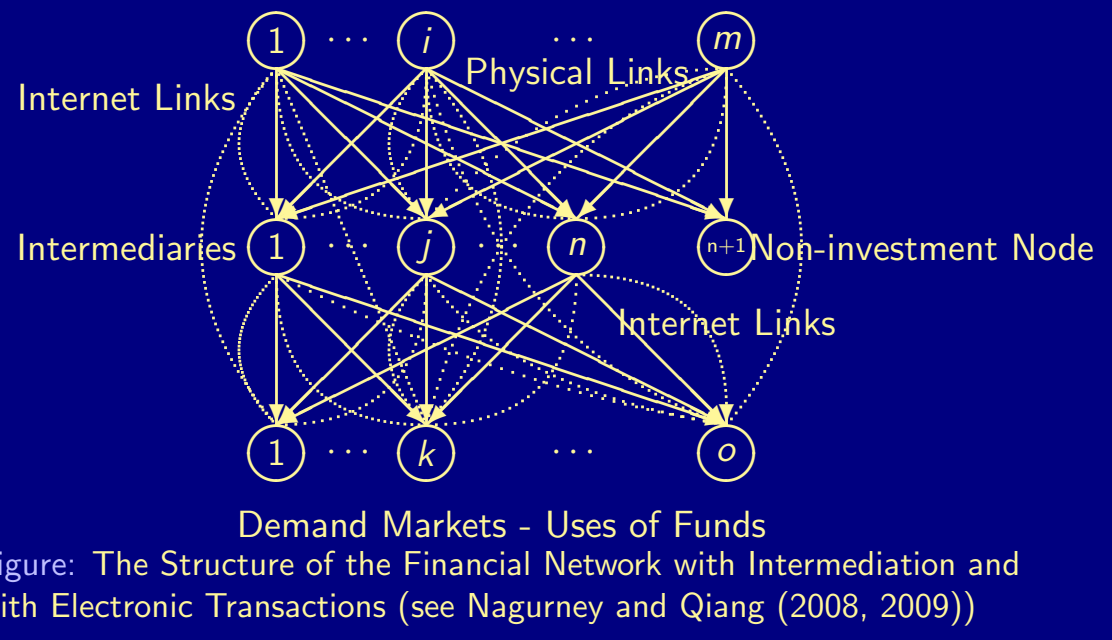




\section{Definition: The Financial Network Performance Measure}

The financial network performance measure, $\mathcal{E}^{F N}$, for a given network topology $\mathcal{G}$ (cf. Figure), and demand price functions $\rho_{3 k}(d) ; k=1,2, \ldots, o$, and available funds held by source agents $S$, where $S$ is the vector of financial funds held by the source agents, is defined as follows

$$
\mathcal{E}^{F N}=\frac{\sum_{k=1}^{o} \frac{d_{k}^{*}}{\rho_{3 k}\left(d^{*}\right)}}{o},
$$

where $o$ is the number of demand markets in the financial network, and $d_{k}^{*}$ and $\rho_{3 k}\left(d^{*}\right)$ denote the equilibrium demand and the equilibrium price for demand market $k$, respectively. 
The financial network performance measure $\mathcal{E}^{F N}$ defined above is actually the average demand to price ratio. It measures the overall (economic) functionality of the financial network. When the network topology $\mathcal{G}$, the demand price functions, and the available funds held by source agents are given, a financial network is considered performing better if it can satisfy higher demands at lower prices (Nagurney and Qiang $(2008,2009))$. 


\section{Definition: Importance of a Financial Network Component}

The importance of a financial network component $g \in \mathcal{G}, I^{F N}(g)$, is measured by the relative financial network performance drop after $g$ is removed from the network

$$
I^{F N}(g)=\frac{\triangle \mathcal{E}^{F N}}{\mathcal{E}^{F N}}=\frac{\mathcal{E}^{F N}(\mathcal{G})-\mathcal{E}^{F N}(\mathcal{G}-g)}{\mathcal{E}^{F N}(\mathcal{G})}
$$

where $\mathcal{G}-g$ is the resulting financial network after component $g$ is removed from network $\mathcal{G}$.

For numerical applications, see Nagurney and Qiang (2008, 2009). 


\section{International Financial Economics}

The advantages of investing internationally have been discussed and studied by many authors (cf. Grubel (1968), Levy and Sarnat (1970), Solnik (1974), Lessard (1976), Adler and Dumas (1983)) and, it is a belief now, that international investments offer far more opportunities than domestic ones.

\section{Moreover, by diversifying across countries with different economic cycles and market structures, investors can reduce the variability of their returns. The greater the international diversification of funds, the less is the risk that investors hold and, furthermore, the lower are the chances of an extreme return in any country.}


In spite of the overwhelming evidence as to the advantages of diversifying internationally, French and Poterba (1991), and Howell and Cozzini (1991) have documented the preference of investors towards domestic assets. Black (1974) and Stulz (1981), among others, suggested that taxation systems and high transaction costs move investors in the direction of domestic assets.

Moreover, other authors (e.g., Solnik (1974), Krugman (1981), Adler and Dumas (1983), Branson and Henderson (1985)) have suggested that investors prefer domestic holdings because their consumption preferences are biased towards the market of their country.

Developments such as the liberalization of eastern European financial markets and the 1992 Maastricht accord within the fifteen European Union members, with agreements of a common monetary system, common financial laws, regulated inflation levels, and, perhaps, in the near future, a common currency, have created a new environment for all investors. 
As a result, new studies must be conducted in order to verify if the investors still behave as previously ascertained, or whether investing internationally will become the norm (as intuition suggests now), rather than the exception.

In any case, studies from major investment banks have documented that investors do turn to international markets. For example, the (formerly named) investment bank Salomon Brothers estimated that the cross-border equity trading, that is, the amount of stock bought by investors in one country from another country, was approximately 1.6 trillion dollars in 1989 alone (Sesit (1989)). 
It is plausible to assume that incorporating multiple countries and currencies increases significantly the complexity of problems. Each country and/or currency has different characteristics and regulations. Investors from different countries do not hold the same expectations and preferences. Assumptions of purely perfect markets, or homogeneous investors cannot hold in an international context.

The factors that contribute to this heterogeneity are due not only to the imperfections in the financial markets (due to, for example, transaction costs, taxes, and fees) but, also, due to the differences of purchasing power among investors of different nationalities. 
Furthermore, the markets are incomplete because investors are restricted from investing in other countries or currencies either by law or by extremely high taxes and transaction costs. For each particular investor-country-currency-security combination a different set of restrictions and regulations applies. 
Due to the differences in nationality among investors and the fact that financial markets based on different currencies are not homogeneous, a series of parity conditions have been identified in international macroeconomics. One of the most significant and commonly used conditions is that of Purchasing Power Parity (PPP), which was first stated by the Swedish economist Gustav Cassel (1918). In particular, PPP is a relationship between weighted average price levels, which are counted in terms of some indices used in every country. Obviously, in order for PPP to hold, all countries must use similar indices, with analogous and accurate ways of computing the consumption preferences of all investors.

According to PPP, a unit of any currency worldwide should have the same purchasing power around the world. It must become clear that PPP does not deal with specific securities and instruments in every country, but with an average estimate. 
On the contrary, the law of one price refers to particular goods, and it states that the exchange-adjusted prices of identical securities must be within transaction costs worldwide. In other words, in the absence of market imperfections, the prices of identical assets must be equal worldwide. 
The empirical evidence concerning the law of one price (Katseli-Papaefstratiou (1979), Isard (1977), Richardson (1978)) documents that violation of the law of one price is rather the rule than the exception. This is mainly due to the fact that goods cannot be purely homogeneous and also because of the differences among the statistical procedures followed by each country. As far as PPP is concerned, empirical results (e.g., Gailliot (1970), Kravis and Lipsey (1978), Roll (1979), Adler and Dumas (1983)) suggest that PPP does not hold in general at a particular point of time or for any time horizon.

Therefore, the assumption of homogeneous investors and markets cannot be used in international financial economics. 
As can be expected, in an international setting, the definition and the derivation of prices are more complicated than in the simple single country case. The rates of return of all securities must be expressed in terms of the same unit. Hence, a basic currency must be selected and all the rates of return have to be expressed in terms of it.

In particular, if we let the random variable $\tilde{r}_{i}$ represent the rate of return of a specific security in terms of the local currency, and we let $e_{i}$ denote the rate of appreciation of the local currency against the basic currency, then the rate of return of this security in terms of the basic currency, is given by:

$$
\begin{gathered}
r_{i}=\left(1+\tilde{r}_{i}\right) \times\left(1+e_{i}\right)-1, \\
r_{i}=\tilde{r}_{i}+e_{i}+\tilde{r}_{i} \times e_{i} .
\end{gathered}
$$


In a large part of the existing literature (cf. Eun and Resnick (1988)), the product $\tilde{r}_{i} \times e_{i}$ is considered to be insignificant in the case of efficient markets, and, therefore, equation (38) can be approximated by:

$$
r_{i} \simeq \tilde{r}_{i}+e_{i} .
$$

Based on the approximation (39), the variance of the return, in terms of the basic currency, is given by:

$$
\operatorname{Var}\left(r_{i}\right)=\operatorname{Var}\left(\tilde{r}_{i}\right)+\operatorname{Var}\left(e_{i}\right)+2 \operatorname{cov}\left(\tilde{r}_{i}, e_{i}\right) .
$$


Let $n$ be the total number of securities available in the economy, and also let $X_{i}$ denote the relative amount invested in security $i$. We can then generalize the previous analysis to a portfolio context, where the variance of portfolio returns, denoted by $\operatorname{Var}\left(r_{p}\right)$, in terms of the basic currency, can be written as:

$$
\begin{gathered}
\operatorname{Var}\left(r_{p}\right)=\sum_{i=1}^{n} X_{i}^{2} \operatorname{Var}\left(r_{i}\right)+\sum_{i=1}^{n} \sum_{\substack{j=1 \\
j \neq i}}^{n} X_{i} X_{j} \operatorname{cov}\left(r_{i}, r_{j}\right), \\
\operatorname{Var}\left(r_{p}\right)=\sum_{i=1}^{n} \sum_{j=1}^{n} X_{i} X_{j} \operatorname{cov}\left(r_{i}, r_{j}\right)
\end{gathered}
$$

where $\operatorname{cov}\left(r_{i}, r_{j}\right)$ represents the covariance between the returns in the markets of currencies $i$ and $j$, and can be approximated by:

$$
\operatorname{cov}\left(r_{i}, r_{j}\right) \simeq \operatorname{cov}\left(\tilde{r}_{i}, \tilde{r}_{j}\right)+\operatorname{cov}\left(e_{i}, e_{j}\right)+2 \operatorname{cov}\left(\tilde{r}_{i}, e_{j}\right)
$$


Using equation (43), (42) can be written as:

$$
\operatorname{Var}\left(r_{p}\right)=\sum_{i=1}^{n} \sum_{j=1}^{n} X_{i} X_{j}\left[\operatorname{cov}\left(\tilde{r}_{i}, \tilde{r}_{j}\right)+\operatorname{cov}\left(e_{i}, e_{j}\right)+2 \operatorname{cov}\left(\tilde{r}_{i}, e_{j}\right)\right]
$$

Grubel (1968) was the first to propose that international investments offer lower return variances, due to the fact that the correlation between market indices from different countries is significantly lower than one. Siegel (1972), in turn, initiated the study of asset pricing among investors of different nationalities. Moreover, Solnik (1974) demonstrated that the variance reduction in international portfolios can be performed even with a small number of securities. He also described the equilibrium holdings of investors from different countries and faced the issue of deriving international equilibrium rates. 
In one of the most important surveys in international macroeconomics, Adler and Dumas (1983) presented an international version of the CAPM, following procedures used by Fischer (1975) and Losq (1977). We will present now the fundamentals of this model, which is a natural extension of the single country CAPM presented earlier. 
In particular, let $r_{p}^{l}$ be the rate of return, in terms of a basic currency, of an optimal portfolio that investors in country I hold, and let $\pi^{l}$ be the inflation rate that the investor from country $I$ faces. Let also $w^{\prime}$ be the wealth of country $I$ and let $w=\sum_{l=1}^{L} w^{l}$ be the wealth of the entire world where $L$ is the number of countries. Let $\alpha^{\prime}$ be the market average degree of relative risk aversion for investors from country $I$, as was defined in equation (26), and, finally, let $\alpha=\sum_{l=1}^{L} \alpha^{l}$. Then, according to the international CAPM, the expected nominal rate of return of security $j$ is given by:

$$
E\left(r_{j}\right)=r_{f}+\alpha \sum_{l=1}^{L}\left(\frac{1}{\alpha^{\prime}}-1\right) w^{\prime} \frac{\operatorname{cov}\left(r_{j}, \pi^{\prime}\right)}{w}+\alpha \operatorname{cov}\left(r_{j}, r_{m}\right) .
$$


In the case where $\alpha^{\prime}=1$, the second component of equation (45) becomes equal to zero. Therefore, the expected return on asset $j$ for investors from country / does not depend on the inflation of their country. Also, due to the fact that the logarithmic utility function has a degree of relative risk aversion equal to one, the investor or the group of investors that gets characterized by $\alpha^{\prime}=1$, is called logarithmic or nationless. In other words, one can say that all the efficient frontiers defined by Markowitz have a common point for all investors in the world. 
According to the "separation theorem" of Black (1972), the work of Solnik (1974), and the paper by Sercu (1980), the equilibrium composition of every investor's portfolio is a combination of two different efficient portfolios, with the first one being the universal or the logarithmic portfolio, and the second one being a portfolio that better hedges the home-inflation of every investor.

According to Solnik, the part of the portfolio that hedges the risk is entirely devoted to the home currency investments, whereas in subsequent papers, this assumption has been relaxed. 
In the case of the model presented by Adler and Dumas, the portfolio holdings in equilibrium were a combination of the logarithmic portfolio with weight $1 / \alpha^{l}$ and of a hedging portfolio with weight $\left(1-1 / \alpha^{\prime}\right)$. In particular, if we group the portfolio holdings for investors from country I into the $n \times 1$ vector $\tilde{w}^{l}$, then the following equation holds:

$$
\tilde{w}^{\prime}=\frac{1}{\alpha^{\prime}} Q^{-1}\left(\tilde{\mu}-\tilde{r}_{f}\right)+\left(1-\frac{1}{\alpha^{\prime}}\right) Q^{-1} q^{\prime},
$$

where $Q$ is the $n \times n$ variance-covariance matrix of nominal rates of return in terms of the basic currency, that is, element $(i, j)$ of matrix $Q$, denoted by $Q_{i j}$, is given by $Q_{i j}=\operatorname{cov}\left(r_{i}, r_{j}\right)$, with $\tilde{\mu}$ being the $n \times 1$ vector of the nominal expected rates of return, $\tilde{r}_{f}$ being an $n \times 1$ vector with all of its elements equal to the risk-free rate $r_{f}$, and $q^{\prime}$ is an $n \times 1$ vector such that $q_{j}^{\prime}=\operatorname{cov}\left(r_{j}, \pi^{\prime}\right)$. 
The model by Solnik (1974) can be viewed as the precursor to contemporary asset pricing models, whereas the single country CAPM can be considered as a special case of the international CAPM in the case of equities (cf. Adler and Dumas (1983)).

As one would expect, a series of different international asset pricing models have appeared in the literature in the last several years, with the vast majority of the models being extensions of the aforementioned CAPM or of the APT by Ross (e.g., Solnik (1983), Levine (1989)). Empirical tests (e.g., Solnik (1977)) have been conducted for most of these models, with the results being controversial with noone being able to claim that one model is much better than another. 
The fact that most of these models examine partial equilibrium, and, therefore, may only study a part of the whole economy, forces the results to be heterodoxical. Moreover, some of the assumptions that have been used are either unrealistic (such as a common degree of risk aversion among all investors of the same country), or the calculation of some mainly abstract variables cannot be done accurately (as is the case for the risk-free asset, and the holdings in a logarithmic utility portfolio). 
It is a common belief, now, that international macroeconomics has experienced significant progress during the last several decades, and that many good ideas and models have been developed. Moreover, almost everyone would also agree that the size and the nature of the problems requires new approaches and new techniques (see, e.g., Nagurney (2003) and Nagurney, Cruz, and Wakolbinger (2004)). 
Financial Transactions

Flows are Relationship Levels

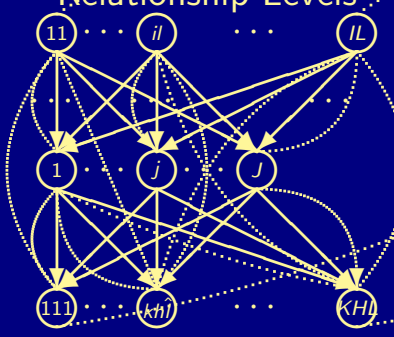

The Supernetwork

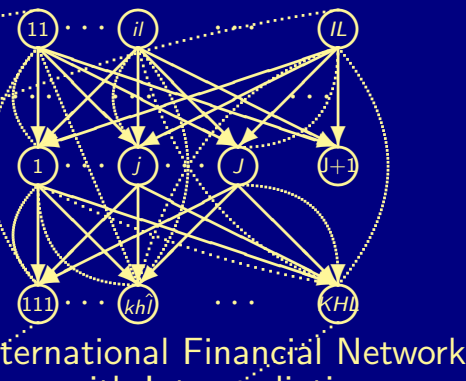
with Interrmediation

\section{Social Network}

Figure: The Multilevel Supernetwork Structure of the Integrated International Financial Network / Social Network System (Nagurney, Cruz, and Wakolbinger (2007)) 


\section{Bibliography}

Adler, M., and Dumas, B., "International Portfolio Choice and Corporation Finance: A Synthesis," Journal of Finance 38 (1983) 925-984.

Arrow, K. J., "An Extension of the Basic Theorems of Classical Welfare Economics," Econometrica 51 (1951) 1305-1323.

Arrow, K. J., "Les Rôle des Valeurs Boursières pour la Répartition la Meilleure des Risques," Econométrie, Centre National de la Récherche Scientifique (1953) 41-48.

Arrow, K. J., Collected Papers of Kenneth Arrow, Belknap Press, Cambridge, Massachusetts, 1969.

Arrow, K. J., and Debreu, G., "Existence of an Equilibrium for a Competitive Economy," Econometrica 22 (1954) 265-290.

Black, F., "Capital Market Equilibrium with Restricted Borrowing," Journal of Business 45 (1972) 444-454. 
Black, F., "International Capital Market Equilibrium with Investment Barriers," Journal of Financial Economics 1 (1974) 337-352.

Black, F., and Litterman, R., "Global Portfolio Optimization," Financial Analysts Journal 48 (1992) 28-43.

Black, F., and Scholes, M. "The Pricing of Options and Corporate Liabilities," Journal of Political Economy 3 (1973) 637-654. Blume, M. E., and Friend, I., "A New Look at the CAPM," Journal of Finance 28 (1973) 147-162.

Branson, W., and Henderson, D., "The Specification and Influence of Asset Markets," in Handbook of International Economics, pp. 749-805, R. W. Jones and P. B. Kenen, Editors, North-Holland, Inc., Amsterdam, The Netherlands, 1985.

Breeden, D. T., "An Intertemporal Asset Pricing Model with Stochastic Consumption and Investment Opportunities," Journal of Financial Economics 7 (1978) 265-296.

Cassel, G., "Abnormal Deviations in International Exchanges," Economic Journal (1918) 413-415. 
Chamberlain, G., "Funds, Factors and Diversification in Arbitrage Pricing Models," Econometrica 51 (1983) 1305-1323.

Connor, G., "A Unified Beta Pricing Theory," Journal of Economic Theory 34 (1984) 13-31.

Cox, J. C., and Huang, C., "Option Pricing Theory and its Applications," in Frontiers of Financial Theory, G.

Constantinides and S. Bhattacharya, Editors, Rowman and Littlefield, Totowa, New Jersey, 1987.

Cox, J. C., Ingersoll, J., and Ross, S. A., "An Intertemporal General Equilibrium Model of Asset Prices," Econometrica 53 (1985) 363-384.

Cox, J. C., Ross, S. A., and Rubinstein, M., "Option Pricing: A Simplified Approach," Journal of Financial Economics 7 (1979) 229-263.

Debreu, G., "The Coefficient of Resource Utilization," Econometrica 19 (1951) 273-292.

Debreu, G., Theory of Value, Yale University Press, New Haven, Connecticut, 1959. 
Debreu, G., "Economies with a Finite Set of Equilibria," Econometrica 38 (1970) 387-392.

Duffie, D., "Stochastic Equilibria: Existence, Spanning Number and the 'No Expected Financial Gain from Trade' Hypothesis," Econometrica 54 (1986) 1161-1184.

Duffie, D., Security Markets. Stochastic Models, Academic Press, Inc., San Diego, California, 1988.

Duffie, D., and Huang, C., "Implementing Arrow-Debreu Equilibria by Continuous Trading of Few Long-Lived Securities,"

Econometrica 53 (1985) 1337-1356.

Dumas, B., "Partial Equilibrium versus General Equilibrium Models of the International Capital Market," in The Handbook of International Macroeconomics, pp. 301-347, F. Van der Ploeg, Editor, Blackwell Publishers, Cambridge, Massachusetts, 1994. Eatwell, J., Milgate, M., and Newman, P., Editors, The New Palgrave: General Equilibrium, W. W. Norton \& Company, Inc., New York, New York, 1989. 
Edwards, W., editor, Utility Theories: Measurements and Applications, Kluwer Academic Publishers, Dordrecht, The Netherlands, 1992.

Elton, E. J., and Gruber, M. J., Modern Portfolio Theory and Investment Analysis, John Wiley \& Sons, third edition, New York, New York, 1987.

Eun, C., and Resnick, B., "Exchange Rate Uncertainty, Forward Contracts, and International Portfolio Selection," The Journal of Finance 43 (1988) 197-215.

Fischer, S., "The Demand for Index Bonds," Journal of Political Economy 83 (1975) 529-534.

Fishburn, P., Utility Theory for Decision Making, John Wiley \& Sons, New York, New York, 1970.

Francis, J. C., "Portfolio Analysis of Asset and Liability Management in Small-, Medium-, and Large-Sized Banks," Journal of Monetary Economics 3 (1978) 112-134.

Francis, J. C., and Archer, S. H., Portfolio Analysis, Prentice-Hall, Inc., Englewood Cliffs, New Jersey, 1979. 
Gailliot, H., "Purchasing Power Parity as an Explanation of Long Term Changes in Exchange Rates," Journal of Money, Credit, and Banking 2 (1970) 348-357.

Gossen, H., Entwicklung der Gesetze des Menschlichen Verkehrs, Prager, Berlin, Germany, 1854.

Grubel, H. G., "Internationally Diversified Portfolios: Welfare Gains and Capital Flows," American Economic Review 58 (1968) 1299-1314.

Henderson, J. M., and Quandt, R. E., Microeconomic Theory: A Mathematical Approach, McGraw-Hill, Inc., New York, New York, 1980.

Hicks, J. R., Value and Capital, Clarendon Press, Oxford, Great Britain, 1939. 
Hirshleifer, J., "Investment Decision under Uncertainty: Choice Theoretic Approaches," Quarterly Journal of Economics 79 (1965) 509-536.

Howell, M., and Cozzini, A., International Equity Flows, International Equity Research, Salomon Brothers, London, Great Britain, 1991.

Huang, C., and Litzenberger, R. H., Foundations for Financial Economics, Prentice-Hall, Inc., Englewood Cliffs, New Jersey, 1988.

Isard, P., "How Far Can We Push The Law of One Price?" American Economic Review 67 (1977) 942-948.

Jevons, W., The Theory of Political Economy, Macmillan Press, Ltd., London, Great Britain, 1871.

Katseli-Papaefstratiou, L., "The Reemergence of the Purchasing Power Parity Doctrine in the 1970's," Special Paper in International Economics 13 (1979). 
Keeney, R. L., and Raiffa, H., Decisions with Multiple Objectives, Cambridge University Press, New York, New York, 1993.

Kolb, R., Options An Introduction, Kolb Publishing Company, Miami, Florida, 1991.

Kravis, I., and Lipsey, R., "Price Behavior in the Light of Balance of Payments Theory," Journal of International Economics 8 (1978) 193-246.

Krugman, P., "Consumption Preferences, Assets Demands, and Distribution Effects in International Financial Markets," working paper no. 651, National Bureau of Economic Research, 1981. Lessard, D., "World Country Industry Relationships in Equity Returns: Implications for Risk Reduction through International Diversification," Financial Analysts Journal 32 (1973) 2-8.

Levine, R., "An International Arbitrage Pricing Model with PPP Deviations," Economic Inquiry 27 (1989) 587-599. 
Levy, H., and Sarnat, M., "International Diversification of Investment Portfolios," American Economic Review 60 (1970) 668-675.

Levy, H., and Sarnat, M., Editors, Financial Decision Making Under Uncertainty, Academic Press, Inc., New York, New York, 1977.

Lintner, J., "The Valuation of Risk Assets and the Selection of Risky Investments in Stock Portfolios and Capital Budgets," Review of Economic Studies 47 (1965) 13-37.

Losq, E., "Commodity Price Uncertainty and Capital Market Equilibrium," Mc-Gill University Mimeo, Montreal, Canada, 1977.

Lucas, R. E., "Asset Prices in an Exchange Economy," Econometrica 46 (1978) 1429-1445.

Luce, R., and Raiffa, H., Games and Decisions, John Wiley \& Sons, Inc., New York, New York, 1957.

Markowitz, H. M., "Portfolio Selection," The Journal of Finance 7 (1952) 77-91. 
Markowitz, H. M., Portfolio Selection: Efficient Diversification of Investments, John Wiley \& Sons, New York, New York, 1959. Merton, R. C., "An Intertemporal Capital Asset Pricing Model," Econometrica 41 (1973) 867-887.

Merton, R. C., "On the Pricing of Corporate Debt: The Risk Structure of Interest Rates," Journal of Finance 29 (1974) 449-470.

Milne, F., Finance Theory and Asset Pricing, Oxford University Press, Inc., New York, New York, 1995.

Milne, F., and Smith, C., "Capital Asset Pricing with Proportional Transaction Costs," Journal of Financial and Qualitative Analysis 15 (1980) 253-265.

Modigliani, F., and Miller, M., "The Cost of Capital, Corporate Finance and the Theory of Corporation Finance," American Economic Review 48 (1958) 261-297.

Mossin, J., "Equilibrium in a Capital Asset Market," Econometrica 34 (1966) 768-783. 
Nagurney, A., Editor, Innovations in Financial and Economic Networks, Edward Elgar Publishing, Cheltenham, England, 2003.

Nagurney, A., "Networks in Finance," in Handbook on IT and Finance, Seese, D., Weinhardt, C., and Schlotmann, F., Editors, Springer, Berlin, Germany, 2008, 383-420.

Nagurney, A., Cruz, J. M., and Wakolbinger, T., "The Co-Evolution and Emergence of Integrated International Financial Networks and Socical Networks: Theory, Analysis, and Computations," in Globalization and Regional Economic Modelling, Cooper, R., Donaghy, K., and Hewings, G., Editors, Springer, Berlin, Germany, 2007, 183-226.

Nagurney, A., and Qiang, Q., "Identification of Critical Nodes and Links in Financial Networks with Intermediation and Electronic Transactions, " in Computational Methods in Financial Engineering, Kontoghiorghes, E. J., Rustem, B., and Winker, P., Editors, Springer, Berlin, Germany, 2008, 273-297. 
Nagurney, A., and Qiang, Q., Fragile Networks: Identifying Vulnerabilities and Synergies in an Uncertain World, John Wiley \& Sons, New York, 2009.

Nagurney, A., and Siokos, S., Financial Networks: Statics and Dynamics, Springer-Verlag, Berlin, Germany.

Office of the Speaker of the U. S. House of Representatives, Stabilizing Housing is Key to America's Recovery, http://speaker. house.gove/newsroom/reports?id=0037 Accessed on November 2, 2008.

Pareto, V., Manuel d' Economie Politique, Giard, Paris, France, 1909.

Pogue, G. A., "An Extension of the Markowitz Portfolio Selection Model to Include Transaction Costs, Short Sales, Leverage Policies, and Taxes," Journal of Finance 25 (1970) 1005-1027.

Pratt, J. E., "Risk Aversion in the Small and in the Large," Econometrica 32 (1964) 122-136. 
Quesnay, F., Tableau Economique, 1758, Reproduced in Facsimile with an Introduction by H. Higgs by the British Economic Society, 1895.

Richardson, J., "Some Empirical Evidence on Commodity Arbitrage and the Law of One Price," Journal of International Economics 8 (1978) 341-352.

Roll, R., "Bias in Fitting the Sharpe Model to Time Series Data," Journal of Financial and Quantitative Analysis 14 (1969) 141-152. Roll, R., "A Critique of the Asset Pricing Theory's Tests. Part 1: On Past and Potential Testability of the Theory," Journal of Financial Economics 4 (1977) 129-176.

Roll, R., "Violations of Purchasing Power Parity and Their Implications for Efficient International Commodity Market," in International Finance and Trade, pp. 133-176, M. Sarnat and G. Szego, Editors, Ballinger, Cambridge, Massachusetts, 1979.

Ross, S. A., "Arbitrage Theory of Capital Asset Pricing," Journal of Economic Theory 13 (1976) 341-360. 
Samuelson, P. A., Foundations of Economic Analysis, Harvard University Press, Cambridge, Massachusetts, 1947.

Savage, L., The Foundations of Statistics, John Wiley \& Sons, Inc., New York, New York, 1954.

Sercu, P., "A Generalization of the International Asset Pricing Model," Revue de l' Association Française de Finance 1 (1980) 91-135.

Sesit, M., "Foreign Investment Makes a Come Back," The Wall Street Journal, September 1, pp. C1 and C14, 1989.

Sharpe, W. F., "A Simplified Model for Portfolio Analysis," Management Science 9 (1963) 277-293.

Sharpe, W. F., "Capital Asset Prices: A Theory of Market Equilibrium under Conditions of Risk," Journal of Finance 19 (1964) 425-443.

Siegel, J., "Risk, Interest, and Forward Exchange," Quarterly Journal of Economics 86 (1972) 303-309. 
Solnik, B., "Equilibrium Model of the International Market," Journal of Economic Theory 8 (1974) 500-524.

Solnik, B., "Testing International Asset Pricing: Some Pessimistic Views," Journal of Finance 32 (1977) 503-511.

Solnik, B., "International Arbitrage Pricing Theory," Journal of Finance 38 (1983) 449-457.

Stapleton, R., and Subrahmanyam, M., editors, Capital Market Equilibrium and Corporate Financial Decisions, JAI Press, Greenwich, Connecticut, 1980.

Stulz, R., "A Model for International Asset Pricing," Journal of Financial Economics 9 (1981) 383-406.

Tobin, J., "Commercial Banks as Creators of Money," in Banking and Monetary Studies, D. Carson, Editor, Irwin, Homewood, Illinois, 1963. 
Tobin, J., "A General Equilibrium Approach to Monetary Theory," Journal of Money, Credit and Banking 1 (1969) 15-29.

Tobin, J., Essays in Macroeconomics, North-Holland, Inc., Amsterdam, The Netherlands, 1971.

Van der Ploeg, F., editor, The Handbook of International Macroeconomics, Blackwell Publishers, Cambridge, Massachusetts, 1994.

Von Neumann, J., and Morgenstern, O., Theory of Games and Economic Behavior, Princeton University Press, Princeton, New Jersey, 1947.

Von Winterfeldt, D., and Edwards, W., Decision Analysis and Behavioral Research, Cambridge University Press, Cambridge, Great Britain, 1986. 
Wald, A., "Über die Eindeutige Positive Losbarkeit der Neuen Productionsgleichungen," Ergebnisse eines Mathematischen Kolloquiums 6 (1935) 12-20.

Wald, A., "Über die Productionsgleichungen der Ökonomischen Wertlehre," Ergebnisse eines Mathematischen Kolloquiums 7 (1936) 1-6.

Walras, L., The Eléments d' Economie Politique Pure, Guillaumin, Paris, France, 1874. 